NASA Technical Memorandum 4193

In-Flight Flow Visualization

Characteristics of the NASA F-18

High Alpha Research Vehicle at

High Angles of Attack

David F. Fisher, John H. Del Frate, and David M. Richwine

MAY 1990

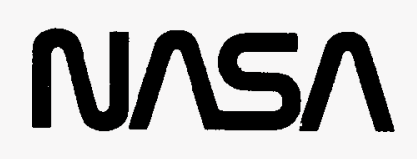


NASA Technical Memorandum 4193

\section{In-Flight Flow Visualization \\ Characteristics of the NASA F-18 \\ High Alpha Research Vehicle at High Angles of Attack}

David F. Fisher and John H. Del Frate

Ames Research Center

Dryden Flight Research Facility

Edwards, California

David M. Richwine

PRC Systems Services, Inc.

Edwards, California

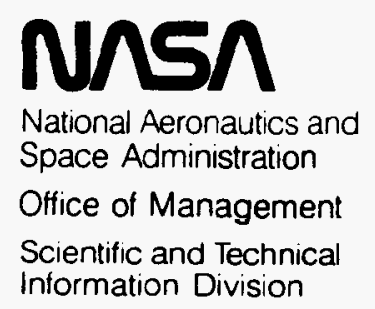




\title{
In-Flight Flow Visualization Characteristics of the NASA F-18 High Alpha Research Vehicle at High Angles of Attack
}

\author{
Davld F. Fisher and John H. Del Frate \\ NASA Ames Research Center \\ Dryden Flight Research Facility \\ Edwards, CA 93523-5000 \\ Davld M. Richwine \\ PRC System Services \\ Edwards, CA 93523-5000
}

\begin{abstract}
Surface and off-surface flow visualization techniques have been used to visualize the three-dimensional separated flows on the NASA F-18 high alpha research vehicle (HARV) at high angles of attack. Results near $\alpha=25^{\circ}$ to $26^{\circ}$ and $\alpha=45^{\circ}$ to $49^{\circ}$ are presented. Both the forebody and leading-edge extension (LEX) vortex cores and breakdown locations were visualized using smoke. Forebody and LEX vortex separation lines on the surface were defined using an emitted fluid technique. A laminar separation bubble was also detected on the nose cone using the emitted fluid technique and was similar to that observed in the wind-tunnel test, but not as extensive. Regions of attached, separated, and vortical flow were noted on the wing and the leading-edge flap using tufts and flow cones, and compared well with limited wind-tunnel results.
\end{abstract}

\section{INTRODUCTION}

In recent years more emphasis has been placed on expanding the envelope of fighter aircraft to include controlled flight at high angles of attack. Fighters such as the F-18 and the F-16 aircraft utilize leading-edge extensions (LEXs) or wing body strakes which provide additional lift caused by the vortical flow these devices develop at a moderate to high angle of attack (1).* However, the prediction and control of this vortical flow and the mutual interactions of the vortices are not well understood. The combined effect of the LEX or wing body strake vortices, as well as the forebody vor-

*Numbers in parentheses designate references at end of paper. tices on the vehicle aerodynamics, must be integrated in a productive manner to avoid any adverse stability and control problems.

Understanding the vortical flow interactions on scale models in wind tunnels can be difficult. Wind tunnel experiments using different scale models have produced conflicting results, even when tested at the same Reynolds number (2). In such subscale-model tests the interaction of the forebody and LEX vortices on 6- and 7-percent-scale F-18 models resulted in apparent lateral stability at both low and high Reynolds numbers for all angles of attack, including stall and poststall regions. However, airplane flight data and wind-tunnel results for the large-scale (16 percent) model at low Reynolds numbers indicated a region of instability near maximum lift. This apparent scale effect has still not been resolved. Understanding such scale effects is essential for successful design of future fighters intended to operate at high angles of attack.

NASA is currently conducting a High Alpha Technology Program to provide design guidelines and new concepts for vortex control on advanced, highly maneuverable aircraft at high angles of attack. This program, which utilizes the F-18 configuration as a validation and demonstration approach, consists of wind-tunnel tests of subscale and full-scale models and components $(3,4)$, calibration for computational fluid dynamics (CFD) technique codes (58), piloted simulations, and full-scale flight testing (9-12).

As part of this investigation, NASA Ames Research Center, Dryden Flight Research Facility (Ames-Dryden) has been conducting extensive flow visualization studies on the NASA F-18 high alpha research vehicle (HARV). 
Surface and off-surface flow visualization results have been obtained in flight on the F-18 HARV highlighting the extensive vortical three-dimensional separated flow at angles of attack up to $55^{\circ}$. The surface flow on the forebody and LEX have been visualized using the emitted fluid technique described in $(9,11,12)$. Tufts and flow cones have also been used to observe the surface flow on the wing, LEX, and vertical tails. The off-surface vortical flows from the forebody and LEX have been visualized by injecting smoke from a smoke generation system into the vortex cores (10-12).

The information presented compares data at $\alpha=25^{\circ}$ to $26^{\circ}$ with data at $\alpha=45^{\circ}$ to $49^{\circ}$, and with some comparison to wind-tunnel results. Water-tunnel and flight offsurface flow visualization are used to understand the mechanisms of the surface flow, where possible. At $\alpha=25^{\circ}$ to $26^{\circ}$, the aircraft is flying at below maximum lift, the LEX vortex core breakdown is near the LEX/eading-edge flap hinge line junction, and the forebody vortices are relatively weak (4). In contrast, at $\alpha=45^{\circ}$ to $48^{\circ}$, the aircraft is flying beyond maximum lift, the LEX vortex core breakdown has moved far forward on the LEX, and the forebody vortices have become much stronger (4). The effect of this forward movement of the LEX vortex core breakdown and the stronger forebody vortex system with increasing angle of attack is shown later in this report.

The flow visualization data obtained from flight is used as an aid for CFD development and in assisting with the understanding of the aircraft's basic aerodynamics. Also, the flight results are compared with surface flow visualization from the ground facilities so the differences between flight and various ground facility results may be better understood.

\section{VEHICLE DESCRIPTION}

The HARV (fig. 1) is a single-place F-18 aircraft built by the McDonnell Douglas and Northrop Corporations and is powered by two General Electric F404-GE-400 afterburning turbofan engines. The aircraft features a midwing with leading- and trailing-edge flaps which operate on a schedule that is a function of angle of attack. For $M_{\infty} \leq$ 0.76 and $\alpha \geq 26^{\circ}$, the leading-edge flap is down $-34^{\circ}$ (maximum), and the trailing-edge flap is at $0^{\circ}$. Leadingedge extensions are mounted on each side of the fuselage from the wing roots to just forward of the windscreen. The aircraft has twin vertical stabilizers canted out from vertical $20^{\circ}$ and differential all-moving horizontal tails.

The F-18 HARV, with current flight control computers and 8.3.3 Programmed Read Only Memory (PROM) set, is flown by NASA in the fighter escort configuration (that is, without stores). The aircraft carries no missiles, and the wingtip sidewinder launch racks have been replaced with special camera pods and wingtip airdata booms. The flight test noseboom has been removed from the aircraft and a NASA flush airdata system has been installed. In this configuration the aircraft has an unrestricted angle-ofattack flight envelope with the center of gravity between 17 and 25 percent mean aerodynamic chord, as defined by the NATOPS (Naval Air Training and Operating Procedures Standardization) manual.

\section{EXPERIMENT DESCRIPTION}

Both off-surface and on-surface flow visualization techniques were used on the F-18 HARV in flight. The offsurface flow visualization used a smoke generation system $(10,11)$, which ducted smoke to the forebody and the LEX apexes to mark the forebody and LEX vortex cores, respectively, at high angles of attack. Flow visualization data were obtained at both steady state and dynamic flight conditions. Time-correlated onboard video and still cameras were used to document the off-surface flow visualization data. The camera locations and smoke generator system locations on the right side of the aircraft are shown in figure 2. The LEX and forebody smoke ports were symmetrically located on both sides of the airplane.

The on-surface flow visualization utilized both the emitted fluid technique $(9,13,14)$, as well as flow cones and tufts $(11,15,16)$. With the emitted fluid technique, a small quantity ( $\sim$ quart) of a fluid, propylene glycol monomethyl ether (PGME), and a toluene-based red dye were slowly emitted out five circumferential rings of llush surface orifices on the F-18 HARV forebody (fig. 3(a)) and three rows of flush-surface orifices on the left LEX (fig. 3(b)) while the aircraft was stabilized at the fight test conditions. As the fluid flowed back along the surface, the PGME evaporated, leaving the dye to mark the surface streamlines. This technique required the pilot to stabilize at the test conditions for 75 to $90 \mathrm{sec}$ while the PGME evaporated and the dye set. An uplink guidance system, similar to that described in (17), was used to assist the pilot in the task.

Tufts were also used for surface flow visualization on the F-18 HARV. Nylon cond tufts approximately 8 in. long were taped to the surface of the wing, the vertical tails, and the fuselage with 5-6 in. of tuft protruding from the tape using the technique of (11). Yam tufts were used on the LEX upper surface and fuselage forward of the engine inlets to prevent damage to the engines should any tufts be ingested. Flow cones $(11,15,16)$ were used in place of the 
nylon cord tufts for some flights. The flow cones used were $3 \mathrm{in}$. long and made of plastic covered with reflective tape.

TEST CONDITIONS - The data reported were obtained during 1-g steady-state flight conditions. The nominal altitudes were between 20,000 and 30,000 ft and the Mach numbers varied from approximately 0.2 to 0.4 . Data were obtained over an angle-of-attack range of $10^{\circ}$ to near $55^{\circ}$, though this report only gives results near $25^{\circ}$ to $26^{\circ}$ and $45^{\circ}$ to $49^{\circ}$. Wing-tuft and flow-cone data were not obtained at $\alpha=45^{\circ}$ to $49^{\circ}$ because of the chase aircraft limitations.

\section{RESULTS AND DISCUSSION}

DATA INTERPRETATION - To understand the flow about the F-18 HARV, a macroscopic view is given using an example from the Ames-Dryden Flow Visualization Water Tunnel. In figure 4, a 1/48-scale model of the aircraft at an angle of attack of $35^{\circ}$ is presented. Using food coloring dye, flow visualization of the forebody and LEX vortices and the separated wing flow is shown. The flow field about the F-18 HARV at high angle of attack is dominated by three-dimensional separated flow. The figure shows strong, tightly wound vortices generated by the sharp-edged LEXs, while weaker vortices developed from the forebody. Interactions can be seen between the forebody and LEX vortices. Flow from the forebody can be seen below the LEX vortex and extending onto the wing. At this angle of attack, the vertical tails are encompassed by turbulent flow caused by the LEX vortex breakdown. The limited amount of dye emitted on the wing indicates large regions of separated flow.

\section{OFF-SURFACE FLOW VISUALIZATION -}

LEX Vortex - Off-surface flow visualization of the LEX vortex using the smoke generation system described in $(10-12)$ is shown in figure 5 for an $\alpha=25.0^{\circ}$ and $\beta=-1.4^{\circ}$. Smoke is emitted from a 1 -in.-diameter port near the LEX apex. The view in this figure is from a $35-\mathrm{mm}$ camera mounted in the wingtip pod looking in at the aircraft fuselage. This flow is very similar to the one shown in the figure 4 water tunnel. A strong vortex is generated by the sharp edge of each LEX, and the vortex core follows a path roughly parallel to the edge. In this case, the smoke marks only the vortex core and not the complete vortex system, which is much larger and extends down to the aircraft surface (4). The trend of the LEX vortex core breakdown point has previously been reported in $(4,10,11)$. As the angle of attack increases, the vortex core breakdown point moves nearer the LEX apex.
At $\alpha=25^{\circ}$ (fig. 5), the path of the vortex core can be seen elevated from the LEX surface, with the vortex core breakdown occurring near the LEX/leading-edge flap hinge line junction. The wingtip photo, taken at a shutter speed of $1 / 1000 \mathrm{sec}$, suggests a spiral-type vortex core breakdown at this angle of attack. The sense of the core spiral breakdown, shown in the figure 5 inset, is opposite in direction to the vortex core rotation. Video images from the left wingtip video camera (with a shutter speed of $1 / 10,000 \mathrm{sec}$ ) confirm this result. Also, this sense of the core spiral breakdown is consistent with the results reported in $(18,19)$.

For comparison, results at $\alpha=49.5^{\circ}$ and $\beta=-5.1^{\circ}$ are shown in figure 6. At this angle of attack and sideslip, the vortex core breakdown has moved forward so that it occurs essentially at the LEX apex. The vortex system has expanded, with the energy of the vortex core dissipated over a larger volume as shown by the smoke.

Forebody Vortex - Off-surface flow visualization of the forebody primary vortex core from the wingtip camera is shown in figure 7 for an $\alpha=25.3^{\circ}$ and $\beta=-0.5^{\circ}$. Smoke was emitted out a 1 -in.-diameter flush port on either side of the nose near F.S. 89 at $\theta=80^{\circ}$ and $280^{\circ}$. The smoke flow analysis was supplemented with video from the left wingtip, from forward-looking video cameras on each tail, and from a forward-looking camera mounted on the pilot's glareshield inside the canopy. The white streaks above and behind the canopy were high cirrus clouds and not smoke from the smoke generator system. At this angle of attack, the vortex pair passed symmetrically back directly over the canopy, and the cores were stable and very close to the aircraft surface. Well aft of the canopy, near the LEX/leading-edge flap hinge line junction, the forebody vortices interacted with the LEX vortices and were pulled down beneath the LEX vortices. The vortices appeared to dissipate over the wing, similar to the water-tunnel flow in figure 4. This location coincides with the LEX vortex core breakdown position shown in figure 5 for nearly the same conditions.

For comparison, the forebody vortices were also examined at an angle of attack of $\sim 45^{\circ}$ where the aircraft was subject to wing rock. Wing rock is the uncommanded, large amplitude, lightly damped rolling motion exhibited by many aircraft and wind-tunnel models at high angles of attack (20-23). For these maneuvers, minimum stick and rudder inputs were requested of the pilot once the aircraft was stabilized at the desired flight conditions. To accomplish this, the pilot centered and held the stick laterally while his feet were off the rudder pedals. Aft stick was required to maintain the desired angle of attack. The figure 8 
time history shows that the aircraft was in a state of wing rock. Roll angle varied from $+29^{\circ}$ to $-21^{\circ}$, while the angle of sideslip varied from $+12^{\circ}$ to $-15^{\circ}$. The two parameters are shown to be in phase, as expected.

Also shown in figure 8 are cross-sectional sketches at the pilot's station, as viewed from behind, showing the locations of the forebody vortex cores as a function of angle of sideslip and roll. The forebody vortex core locations were interpreted from video images taken by the F-18 HARV vertical tail cameras. During the sideslip excursions, the vortex cores became highly transient. As the aircraft passed through $0^{\circ}$ sideslip, the tail-mounted video cameras discerned a slight lag in the vortex core position.

Selected wingtip photos (with insets for clarity) of the forebody vortex cores taken during this maneuver are noted in figure 8 and are presented in figure 9. At $\beta \sim 0^{\circ}$ (fig. 9(a)), the forebody vortex pair interacted with the LEX vortices slightly aft of the canopy and were pulled down beneath the LEX vortices and dissipated outward. With sideslip (figs. 9(b) and (c)), the windward vortex core was elevated from the surface, especially aft of the canopy. Near maximum sideslip, the windward forebody vortex core moved up over the top of the canopy (figs. 8 and $9(\mathrm{~b})$ ) and aft, crossing the aircraft centerline near the midchord of the wing, as determined by the tail video cameras. At $\beta=$ $-5.5^{\circ}$ (fig. 9(c)), the leeward vortex core can be seen just below the windward vortex core foreward of the canopy. As the leeward forebody vortex approached the pilot's station, it interacted with the LEX leeward vortex. The leeward forebody vortex was pulled sharply down beneath the leeward LEX vortex and then dissipated up and out. This vortex interaction correlated with the location of the LEX vortex core breakdown position for similar conditions shown in figure 6. As the sideslip value increased further, this sharp downward tum of the leeward vortex moved forward towards the LEX apex, as determined by the wingtip video camera.

SURFACE FLOW VISUALIZATION - As previously mentioned, surface flow visualization was documented on the F-18 HARV using the emitted fluid technique, flow cones, and tufts. The results using the emitted fluid technique were documented postflight with the aircraft parked on the ramp. The flow cone and tuft results reported in this report were photographed with the onboard wingtip 35-mm still camera and from a chase aircraft in close proximity to the F-18 HARV with a 70-mm film still camera. The tufts were also filmed simultaneously with slow motion ( 78 to 130 frames/sec (f/s)) $35-\mathrm{mm}$ motion picture film from the chase aircraft.
Emitted Fluid Technique on Forebody, $\alpha=26^{\circ}-$ Surface flow visualization on the F-18 HARV aircraft using the emitted fluid technique on the forebody is shown in figure 10. The surface streamlines are marked on the aircraft surface with red dye. Where the flow streamlines merge, lines of separation are defined and, conversely, where the streamlines diverge, lines of reattachment are defined. The line of separation is more easily defined since the fluid flows toward the separation line. At reattachment, the fluid flows away and is only well defined near a source of fluid. Note that when the fluid enters the joints and cracks on the aircraft surface, there is some displacement or disappearance of the dye traces. This could not be completely avoided and should be neglected. A schematic of the flow about the forebody is shown in the figure 10(a) inset and identifies pairs of primary and secondary vortices. Only the primary vortex was shown previously with the smoke flow (fig. 5). Both primary and secondary forebody separation lines are clearly visible in the figure 10 photos and appear to be nearly symmetrical (fig. 10(b)). The secondary vortex separation line is not apparent on the forebody until about F.S. 142. Near the nose, indications of a laminar separation bubble and boundary layer transition are subtle and are discussed in detail later in this section.

A time history of Mach number, altitude, angle of attack, angle of sideslip, and Reynolds number for the results shown in figure 10 is given in figure 11. The PGME and dye mixture was emitted during the first $20 \mathrm{sec}$ of the maneuver. This test point was one of the best obtained. The flight conditions, $\alpha$ and $\beta$, were held nearly constant throughout the test point, as shown. The standard deviation about the $26^{\circ}$ mean angle of attack during this time period was $0.3^{\circ}$. Maximum deviations of $\pm 0.8^{\circ}$ were observed. At the same time, the angle of sideslip was $0^{\circ}$ with a standard deviation of $0.4^{\circ}$ about that value with maximum deviations of $\pm 1^{\circ}$. The small deviations in angle of attack and sideslip and a low fluid flow rate account for the sharp, well-defined surface streamlines.

Emitted Fluid Technique on Forehody, $\alpha=47^{\circ}$ For comparison, an example of the forebody surface flow visualization at an angle of attack of $47^{\circ}$ is shown in figure 12. Two observations can be made from these photos: (1) The surface streamline traces are more smeared than in the previous example, and (2) the first indications of the secondary vortex separation lines have moved much farther forward on the nose. At $\alpha=26^{\circ}$ (fig. 10), the secondary vortex separation lines were not evident until near F.S. 142. At $\alpha=47^{\circ}$ (fig. 12), the secondary vortex separation lines can be seen near F.S. 85 . This indicates a stronger, more 
fully developed vortex system that forms nearer the apex at $\alpha=47^{\circ}$ than at $\alpha=26^{\circ}$.

The time history of the aircraft conditions corresponding to figure 12 is shown in figure 13. Both angle of attack and angle of sideslip were not held as constant as the previous example. The standard deviation of angle of attack was $0.7^{\circ}$ with maximum deviations of $\pm 1.5^{\circ}$, while the standard deviation of sideslip was $2.5^{\circ}$ with maximum excursion to $\pm 4^{\circ}$ during the first $45 \mathrm{sec}$. At $\alpha=47^{\circ}$, the aircraft was in a mild wing-rock condition. Due to the low effectiveness of the rudders and ailerons at this angle of attack, the pilot was unable to stabilize the aircraft as well, causing the flow streamlines to be smeared.

The separation lines at $\alpha=47^{\circ}$, although smeared, appear to be nearly symmetrical (fig. 12(b)). In actuality, the vortices and respective separation lines are most likely moving to the left and right during the maneuver, similar to that shown in figure 8 , but to a lesser extent. This causes the apparent separation lines to be much wider than at $\alpha=26^{\circ}$. The edges of the wide separation lines are felt to be the limits to which they move. This is most noticeable on the aft portion of the forebody, especially aft of F.S. 142 (fig. 12(a)).

Forebody Boundary Layer Transition - Further and more definitive indications of boundary layer transition on the forebody were evident at $\alpha=47^{\circ}$ (fig. 12(a)). The effect of the boundary layer transition is seen in the closeup view in figure 14. A large dye puddle is noted extending intermittently from $\theta=240^{\circ}$ at F.S. 70 to almost F.S. 109 and $\theta=247^{\circ}$, as shown on the left side. Though not presented, symmetrical results were obtained on the left side at $\theta=120^{\circ}$ and $113^{\circ}$ at F.S. 70 and 109 , respectively. These puddles are felt to be the result of a laminar separation bubble (LSB) with boundary layer transition occurring downstream. Note that where screwhead protuberances around the plugged smoker port (that would cause premature transition) are present, this dye puddle did not occur. Also notice that the fluid windward of the laminar separation bubble flowed toward the bubble and the fluid leeward of the bubble flowed away. This indicates that the flow reattached turbulently past the very localized laminar separation bubble and that this is not the primary vortex separation line.

To further investigate this phenomenon, selected flush static orifices located forward of F.S. 70 normally used for the flush airdata system (FADS) were connected to the surface flow visualization system and several flights were flown. The results at $\alpha=49^{\circ}$ are shown in figure 15. A dark line can be seen just behind the port at $\theta=180^{\circ}$ at F.S. 60.14, extending just forward of the ports at $\theta=135^{\circ}$ and $215^{\circ}$ at F.S. 60.71 (fig. 15(a)). At F.S. 60.71 (fig. 15(b)), the laminar separation bubble is at $\theta_{\text {LSB }} \sim 230^{\circ}$ on the left side ( $\theta_{\text {LSB }} \sim 130^{\circ}$ on the right). Farther aft the values are: F.S. $61.57, \theta_{L S B} \sim 235^{\circ}\left(\theta_{L S B} \sim 125^{\circ}\right)$; F.S. $62.5,240^{\circ}$ $\left(120^{\circ}\right)$; and F.S. $70,240^{\circ}\left(120^{\circ}\right)$. In the wake of the screwheads at F.S. 73, the puddling effect is absent, indicating that the protuberances of the screwheads caused boundary layer transition. However, farther aft on the nose cone the puddling effect is again present. The screwhead protuberances around the smoker port at F.S. 89 also caused a transition (also noted in fig. 14). The fluid seen flowing from the orifices at $90^{\circ}, 180^{\circ}$, and $270^{\circ}$ at F.S. 60.71 (fig. 15(a) and (b)) should be ignored. These orifices were still connected to the pressure transducers, and the fluid apparently entered the orifices during the test point and later ran out.

From the wind-tunnel results of (3), a similar but more extensive laminar separation bubble (fig. 16(a)) was noted extending alongside the forebody from the nose apex to beyond the LEX apex F.S. As shown in the forebody pressure distribution in figure 16(b) from (3), the laminar separation bubble and transition occurred slightly leeward of the point of maximum suction, $\theta \sim 248^{\circ}\left(\theta \sim 114^{\circ}\right)$ from the windward ray at F.S. 70 , and at the beginning of an adverse pressure gradient (increasing pressure in the direction of flow). This transition, caused by an adverse pressure gradient, is similar to what has been obtained on laminar flow airfoils. It is not surprising that the longitudinal extent of the laminar separation bubble is much greater for the wind tunnel. The attachment line on the windwand axis would be laminar much farther aft for the lower Reynolds number data from the tunnel. This is because the attachment line boundary layer transition location is dependent upon the momentum thickness Reynolds number which is a function of angle of attack (sweep for airfoils), forebody radius (wing leadingedge radius), and unit Reynolds number (24).

Emitted Fluid Technique on LEX, $\alpha=26^{\circ}$ - Surface flow visualization using the emitted fluid technique on the left LEX for an angle of attack of $26^{\circ}$ is shown in figure 17. The time history of the test parameters for this test point is shown in figure 11. At $\alpha=25^{\circ}$, the breakdown point for the LEX primary vortex core was shown to be very near the LEX/leading-edge flap hinge line junction (fig. 5). Since this is aft of the LEX, the LEX surface flow should be strongly influenced by the strong, tightly wound vortex over it. A schematic of the flow about the LEX is illustrated in the figure 17(a) inset. The separation line for the primary vortex, $S_{1}$, is defined by the sharp edge of the LEX. The fluid emitted from the orifices mark the surface streamlines 
which merge into a wide longitudinal band along the upper surface of the LEX. The inboard edge of the wide band defines the secondary separation line, $S_{2}$, with the outboard edge of the band the result of the tertiary separation line, $S_{3}$. Similar results showing the secondary and tertiary separation lines were obtained on an HP-115 airplane with a highly swept wing in flight using kaolin, red dye, and water (25). The wide band in figure 17 is a weak reattachment zone. This is illustrated by the concentration of dye at the band edges near F.S. 253 (fig. 17(b)) and the slightly divergent streamlines between F.S. 253 and F.S. 296 (fig. 17(b) and (c)). In figure $17(\mathrm{c})$, it can be seen qualitatively that the slope of the streamlines toward the secondary vortex separation line is greater than for the tertiary vortex separation line.

Emitted Fluid Technique on LEX , $\alpha=47^{\circ}-$ In figure 18, the LEX surface flow streamlines are for an $\alpha=$ $47^{\circ}$. At this angle of attack, the LEX vortex breakdown point is very near the LEX apex. Even though the primary vortex core has already experienced breakdown, the secondary and tertiary separation lines are still present, although somewhat smeared (fig. 18(a-d)). Apparently the vortex still persists for some time after core breakdown, although weaker in strength and dissipating. At least part of the smearing shown in the figure is caused by the mild wing-rock condition previously discussed and shown in figure 13. There were also some interesting striations in the surface flow visualization near F.S. 357 (fig. 18(d)) at this angle of attack. This could be due to the helical motion of the secondary and tertiary vortices moving on the LEX. The secondary and tertiary separation lines have also moved significantly outboard at F.S. $357, \alpha=47^{\circ}$, as compared to $26^{\circ}$.

Flow Tuft and Flow Cone Technique on Wing - Surface flow visualization of the surface flow on the right wing and aft fuselage was obtained using flow cones and tufts. The results at $\alpha \sim 20^{\circ}, 25^{\circ}$, and $30^{\circ}$ are presented in figures 19-21 from flight and unpublished wind-tunnel data. The analysis of the still photos presented from flight were supplemented with slow-motion film photography that had been converted to 3/4-in. video tape for analysis.

At $\alpha \sim 20^{\circ}$, the vortex core breakdown was just forward and slightly outboard of the vertical tails. The separation line band similar to that shown by the emitted fluid technique can be identified on the LEX where the tufts merge; however, the tuft spacing was not fine enough to identify the secondary separation line from the tertiary separation line. At $\alpha \sim 20^{\circ}$ (fig. 19(a)), the influence of the LEX vortex system was evident on the inboard portion of the wing, causing the flow to stay attached and the streamlines, in general, to be directed outward and aft. Note in the figure that the smoke shows only the vortex core and not the total vortex system. An extensive amount of reversed flow and surface vortical flow was present on the main wing just aft of the leading-edge flap/wing junction. Evidence indicating the presence of three counterclockwise surface vortices can be seen with the tufts near midspan, as shown in the inset. Near the wingtip the tufts indicated that a clockwise surface vortex was present. This interpretation of the wing flow was aided by slow-motion photography filmed at $78 \mathrm{f} / \mathrm{s}$. The view of flow cones on the leadingedge flap (fig. 19(b)) was obtained from a different flight at nearly identical conditions. Most of the inboard leadingedge flap at $\alpha \sim 20^{\circ}$ had attached flow, while the outboard leading-edge flap had reversed flow.

Results on the wing at $\alpha \sim 25^{\circ}$ are shown in figure 20 . Again, the separation line band on the LEX can be seen as well as the attached, outward flow on the inboard portion of the wing (fig. 20(a)) caused by the LEX vortex. Much of the flow on the wing directly aft of the wing/leading-edge flap junction was reversed, with only one counterclockwise surface vortex observed on the wing near midspan. The clockwise vortex at the wingtip had moved slightly farther aft (fig. 20(a)). At this angle of attack, increasingly more of the inboard leading-edge flap (fig. 20(b)) had become reversed than at $\alpha \sim 20^{\circ}$.

For comparison, an unpublished wind-tunnel oil flow of a 0.06 -scale-model F-18 aircraft at $\alpha=25^{\circ}$ is shown in figure 20(c). The outboard and aft flow on the inboard portion of the wing can be clearly seen because of the LEX vortex system and agree well with that observed in flight. The LEX separation line band can be seen extending from the LEX to the wing trailing edge. The reversed flow on the outboard flap and the surface vortex on the outboard wing agree well with the limited tuft and flow-cone results from flight.

At $\alpha \sim 30^{\circ}$ (fig. 21), the flow on the wing is similar to that at $\alpha \sim 20^{\circ}$ and $25^{\circ}$. Slightly less of the inboard wing appears to be affected by the LEX vortex (fig. 21(a)), with less attached flow on the inboard wing than at $\alpha \sim 20^{\circ}$ or $25^{\circ}$. More of the wing has reversed or separated flow. At the higher angle of attack, more of the leading-edge flap has become separated (that is, reversed flow), as shown in figures 21(a) and (b).

\section{SUMMARY OF RESULTS}

Flow visualization results of the vortical flow on the forebody leading-edge extensions (LEXs) and wing have 
been reported from the F-18 high alpha research vehicle (HARV) at angles of attack near $25^{\circ}$ to $26^{\circ}$ and $45^{\circ}$ to $49^{\circ}$. A smoke generator system was used to visualize the offsurface forebody and LEX vortices. An emitted fluid technique was used to show the surface flow streamlines and to identify separation lines on the forebody and LEX. Flow cones and tufts were used to document attached and separated surface flow on the wing, and on portions of the aft fuselage and LEX.

A strong, tightly wound primary vortex was generated by the LEX at $\alpha \sim 25^{\circ}$. The vortex breakdown occurred near the LEX/leading-edge flap hinge line junction, and a spiral breakdown was suggested. At $\alpha=49.5^{\circ}, \beta=$ $-5.1^{\circ}$, the LEX primary vortex core breakdown point was shown to be near the LEX apex.

The forebody vortex pairs were shown to interact with the LEX vortices and correlated with the LEX vortex core breakdown position. At $\alpha \sim 25^{\circ}$ to $26^{\circ}$ and $\beta \sim 0^{\circ}$, the forebody primary vortex pair were symmetrical and stable, and were pulled beneath the LEX vortices near the LEX/leading-edge flap hinge line junction (very near the LEX vortex core breakdown position). At $\alpha=45^{\circ}$ to $49^{\circ}$, aircraft was in wing rock and the forebody vortex pairs were highly transient. At $\beta \sim 0^{\circ}$, the forebody/LEX vortex interaction was slightly aft of the canopy. As the sideslip value increased, this interaction between the leeward forebody vortex and the leeward LEX vortex moved forward towards the LEX apex and appeared to correlate with the LEX vortex core breakdown position. The windward vortex was elevated at the same time, especially aft of the canopy.

Primary and secondary vortex separation lines were identified on the forebody in flight. The origin of the primary and secondary vortex separation lines was much nearer to the nose apex at $47^{\circ}$ than at $26^{\circ}$.

A laminar separation bubble was present on the nose cone, particularly at the highest angles of attack and was similar to wind-tunnel results, though not as extensive.

Secondary and tertiary separation lines were indentified on the LEX, even at the highest angle of attack where the primary vortex core breakdown had already occurred.

Extensive regions of separated, reversed, and vortical flow were observed on the F-18 HARV wing at $\alpha \sim 20^{\circ}$, $25^{\circ}$, and $30^{\circ}$ and are in general agreement with wind-tunnel oil flows. The influence of the LEX vortex at these angles of attack appears to keep the flow attached on the inboard portion of the wing.

\section{NOMENCLATURE}

CFD computational fluid dynamics

$C_{p} \quad$ pressure coefficient

FADS flush airdata system

F.S. fuselage station, in. (nose apex at 59.82 in.)

f/s frames/sec

$g$

load factor normal to longitudinal axis of aircraft

HARV high alpha research vehicle

$h_{p}$

LEX

geopotential altitude, $\mathrm{ft}$

leading-edge extension

LSB laminar separation bubble

$M_{\infty}$

free-stream Mach number

NATOPS Naval Air Training and Operating Procedures Standardization

PGME propylene glycol monomethyl ether

PROM Programmed Read Only Memory

$R \quad$ reattachment line location

$R e_{\bar{c}} \quad$ Reynolds number based on mean aerodynamic chord

$S_{0}$

$S_{1}$

$S_{2}$

$S_{3}$

$V_{N}$

$\alpha$

stagnation line location

primary separation line location

secondary separation line location

tertiary separation line location

normal component of free-stream velocity

alpha, angle of attack, right wingtip angle-ofattack vane corrected for upwash and boom bending, deg

angle of sideslip, average of left and right wingtip sideslip vanes corrected for angle of attack, deg

forebody cross-section angular location

( $0^{\circ}$ is bottom centerline, positive is

clockwise as seen from a front view,

$0^{\circ}$ to $\left.360^{\circ}\right)$, deg

aircraft roll angle, deg 


\section{REFERENCES}

1. Skow, A.M., and G.E. Erickson, "Modem Fighter Aircraft Design for High-Angle-of-Attack Maneuvering," AGARD LS-121, paper no. 4, 1982.

2. Erickson, Gary E., Water Tunnel Flow Visualization and Wind Tunnel Data Analysis of the F/A-18, NASA CR-165859, 1982.

3. Banks, Daniel W., "Wind-Tunnel Investigation of the Forebody Aerodynamics of a Vortex-Lift Fighter Configuration at High Angles of Attack," SAE Paper 881419, Oct. 1988.

4. Erickson, G.E., R.M. Hall, D.W. Banks, J.H. Del Frate, J.A. Schreiner, R.J. Hanley, and C.T. Pulley, "Experimental Investigation of the F/A-18 Vortex Flows at Subsonic Through Transonic Speeds, Invited Paper," AIAA-89-2222, July-Aug. 1989.

5. Thomas, James L., Robert W. Walters, Taekyu Reu, Farhad Ghaffari, Robert P. Weston, and James M. Luckring, "A Patched-Grid Algorithm for Complex Configurations Directed Towards the F/A-18 Aircraft," AIAA-89-0121, Jan. 1989.

6. Ghaffari, F., J.M. Luckring, J.L. Thomas, and B.L. Bates, "Navier-Stokes Solutions about the F/A-18 Forebody-LEX Configuration," AIAA-89-0338, Jan. 1989.

7. Schiff, Lewis B., Russell M. Cummings, Reese L. Sorenson, and Yehia M. Rizk, "Numerical Simulation of High-Incidence Flow over the F-18 Fuselage Forebody," AIAA-89-0339, Jan. 1989.

8. Schiff, Lewis B., Russell M. Cummings, Reese L. Sorenson, and Yehia M. Rizk, "Numerical Simulation of F-18 Fuselage Forebody Flows at Large Angles of Attack," presented at the NASA/AIAA CFD Conference, Moffett Field, Califomia, Mar. 7-9, 1989.

9. Fisher, David F., David M. Richwine, and Daniel W. Banks, Surface Flow Visualization of Separated Flows on the Forebody of an F-18 Aircraft and WindTunnel Model, NASA TM-100436, 1988.

10. Curry, Robert E., and David M. Richwine, "An Airbome System for Vortex Flow Visualization on the
F-18 High-Alpha Research Vehicle," AIAA-88-4671CP, Sept. 1988.

11. Fisher, David F., and Robert R. Meyer, Jr., Flow Visualization Techniques for Flight Research, NASA TM-100455, 1988.

12. Fisher, D.F., R.E. Curry, J.H. Del Frate, and D.M. Richwine, "In-Flight Flow Visualization Techniques on a Vortex-Lift Fighter Aircraft," presented at the Fifth International Symposium on Flow Visualization, Prague, Czechoslovakia, Aug. 1989.

13. Belevtsov, N., R.E. Brumby, and J.P. Hughes, "InFlight Flow Visualization, A Fluid Approach," SFTE, 14th Annual Symposium Proceedings, Aug. 1983, pp. $4.2-1$ to $4.2-7$.

14. Hughes, J.P., R.E. Brumby, and N. Belevtsov, "Flow Visualization From the Ground Up," AIAA-83-2691, 1983.

15. Crowder, James P., "Flow Visualization Techniques Applied to Full-Scale Vehicles," AIAA-87-2421, 1987.

16. Crowder, James P., and Paul E. Robertson, "Flow Cones for Airplane Flight Test Flow Visualization," in Flow Visualization III, W.J. Yang, ed., Hemisphere Publ. Corp., 1985, pp. 60-64.

17. Meyer, R.R., Jr., and Comdr. E.T. Schneider, "RealTime Pilot Guidance for Improved Flight Test Maneuvers," AIAA-83-2747, Nov. 1983.

18. Payne, Francis M., "The Structure of Leading Edge Vortex Flows Including Vortex Breakdown," Ph.D. Dissertation, University of Notre Dame, Notre Dame, Indiana, May 1987.

19. Solignac, J.L., and O. Leuchter, "Etudes Experimentales D'Ecoulements Tourbillionnaires Soumis a des Effets de Gradient de Pression Adverse" ("Experimental Studies of Vortical Flows Under the Effects of Adverse Pressure Gradients"), AGARD-CP-342, paper no. 28, Apr. 1983.

20. Nguyen, L.T., L. Yip, and J.R. Chambers, "SelfInduced Wing Rock of Slender Delta Wings," AIAA81-1883, Aug. 1981.

21. Ross, A. Jean, and Luat T. Nguyen, "Some Observations Regarding Wing Rock Oscillations at High Angles of Attack," AIAA-88-4371-CP, Aug. 1988. 
22. Manoeuvre Limitations of Combat Aircraft," AGARD-AR-155A, Aug. 1979.

23. Ericsson, L.E., "Further Analysis of Wing Rock Generated by Forebody Vortices," AIAA-882597-CP, June 1988 (replaces R.A.E. Technical Report 74022, A.R.C. 35 554).
24. Pfenninger, Werner, "Laminar Flow Control, Laminarization," a Special Course on Concepts for Drag Reduction, AGARD R-654, 1977.

25. Bisgood, P.L., "The Application of a Surface Flow-Visualisation Technique in Flight," A.R.C. R\&M no. 3769, Feb. 1974.

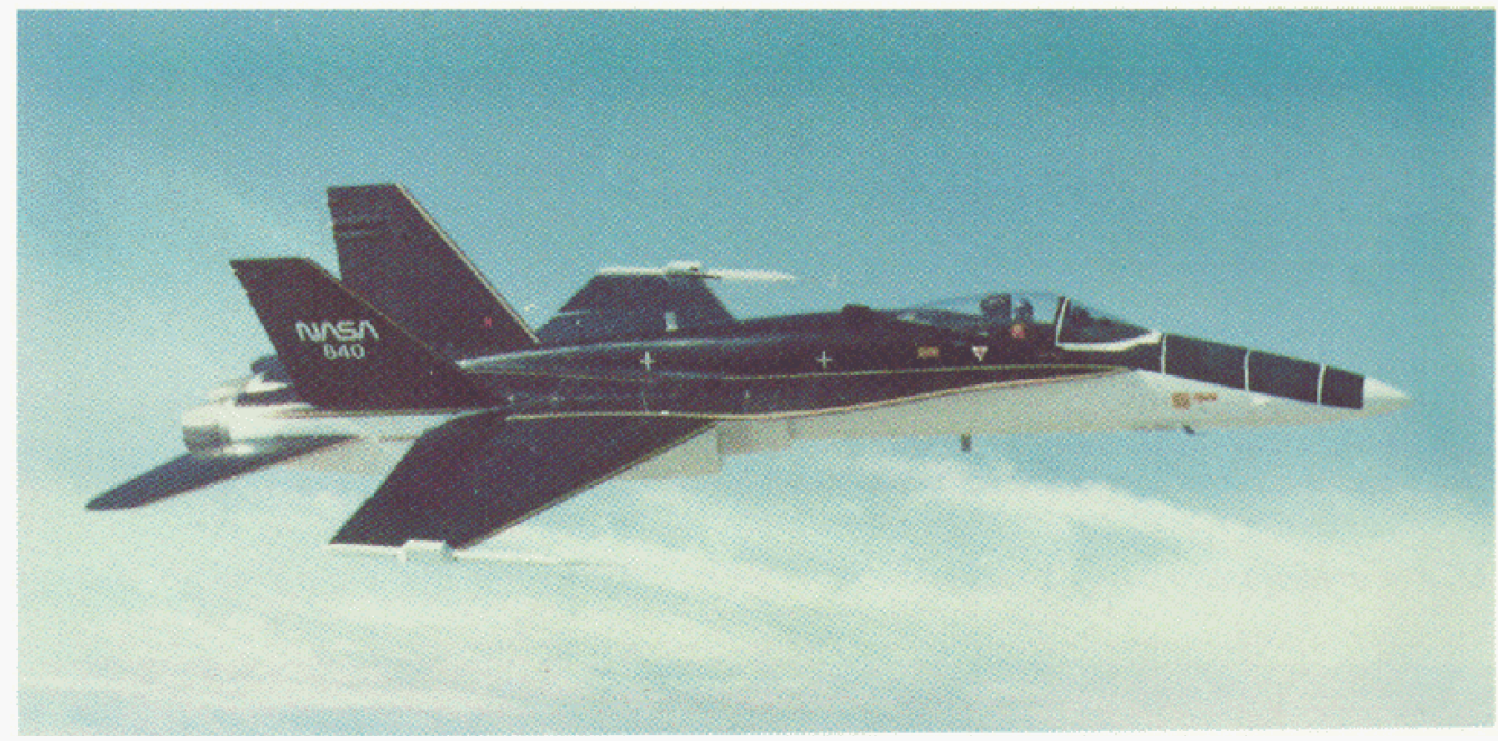

EC89 0062-001

Figure 1. The F-18 HARV.

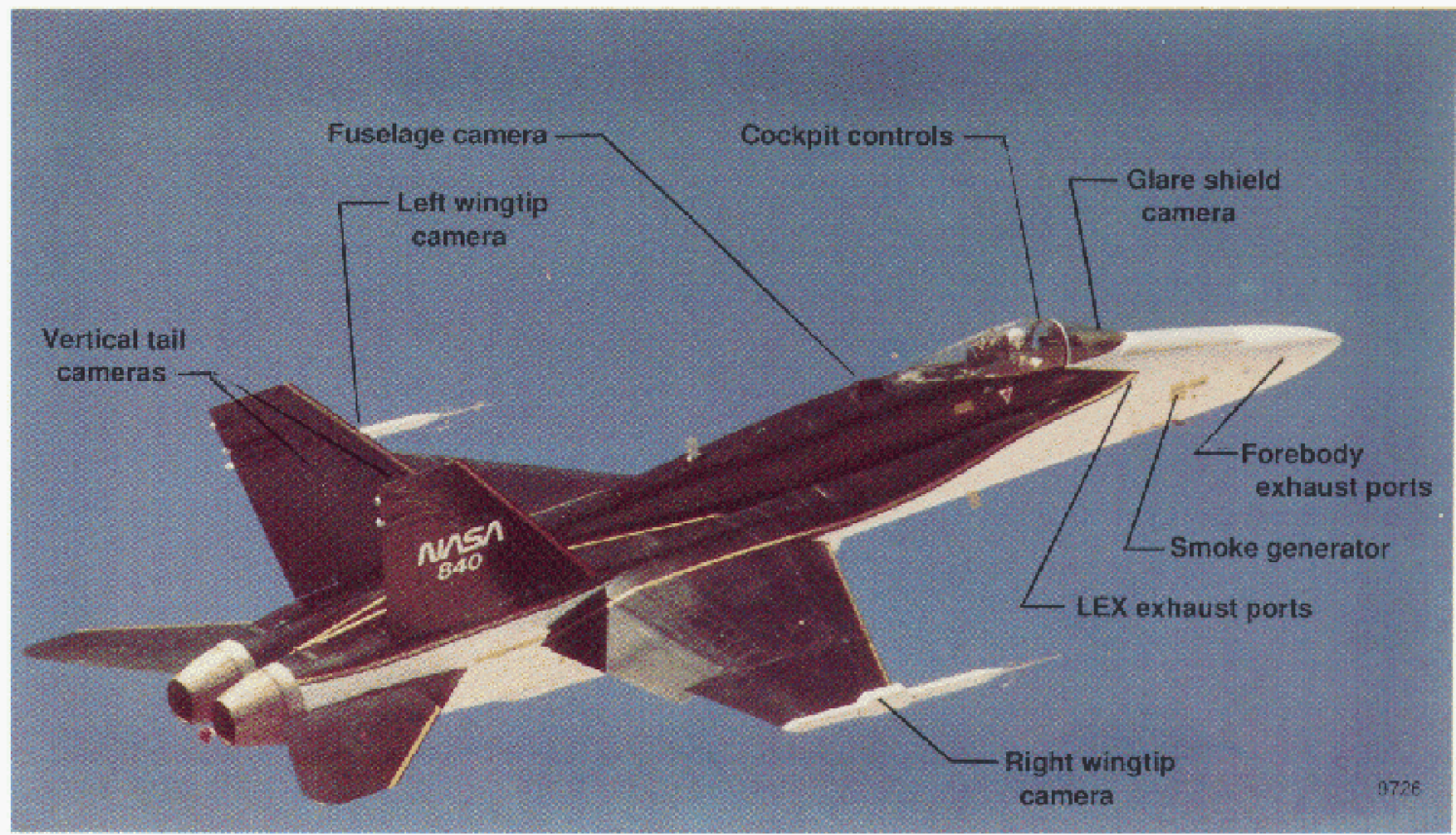

Figure 2. Locations of onboard cameras and smoke generator system on F-18 HARV. 


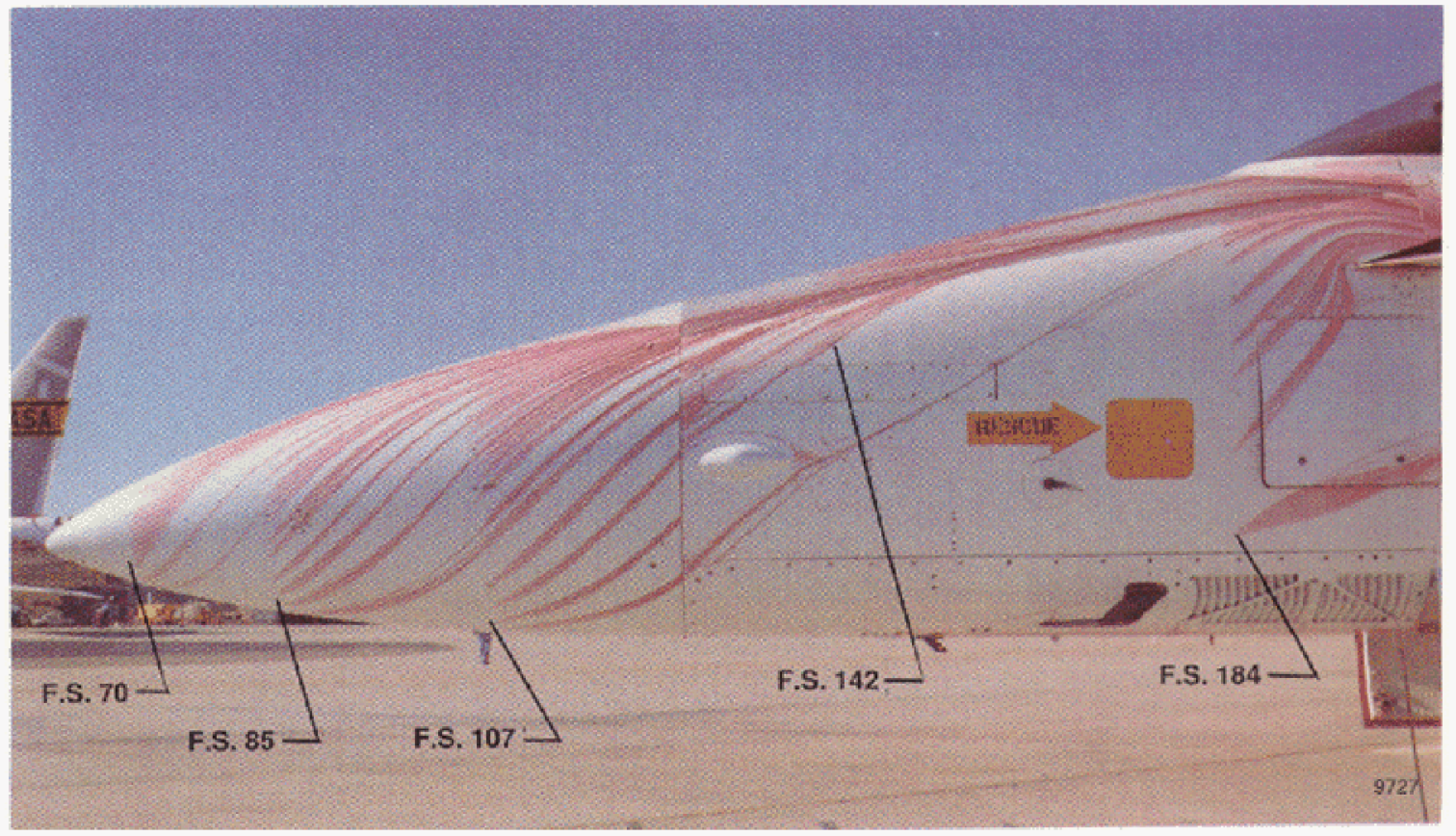

(a) Forebody locations.

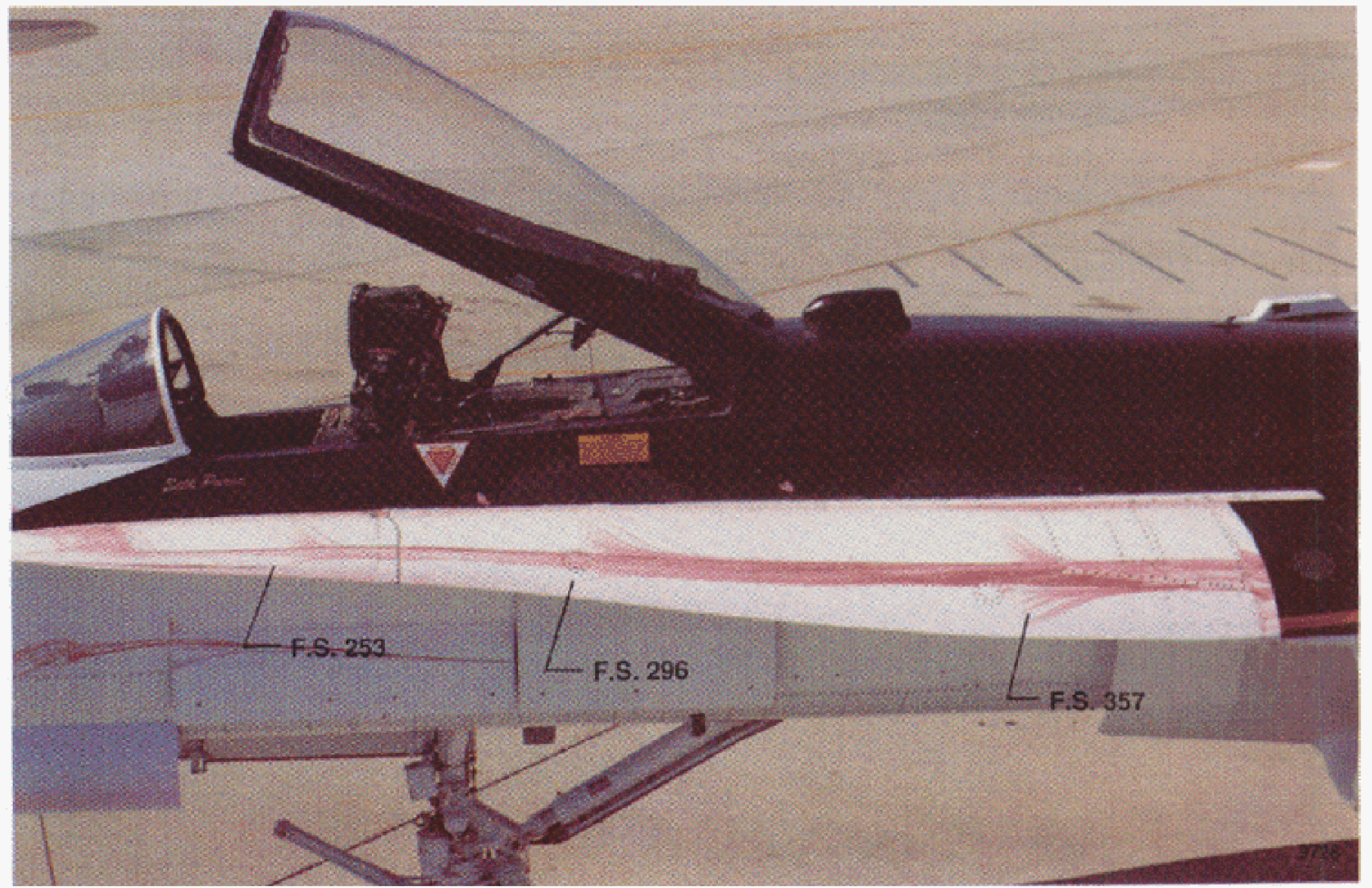

(b) LEX locations.

Figure 3. Locations of flush surface-static orifices on F-18 HARV. 


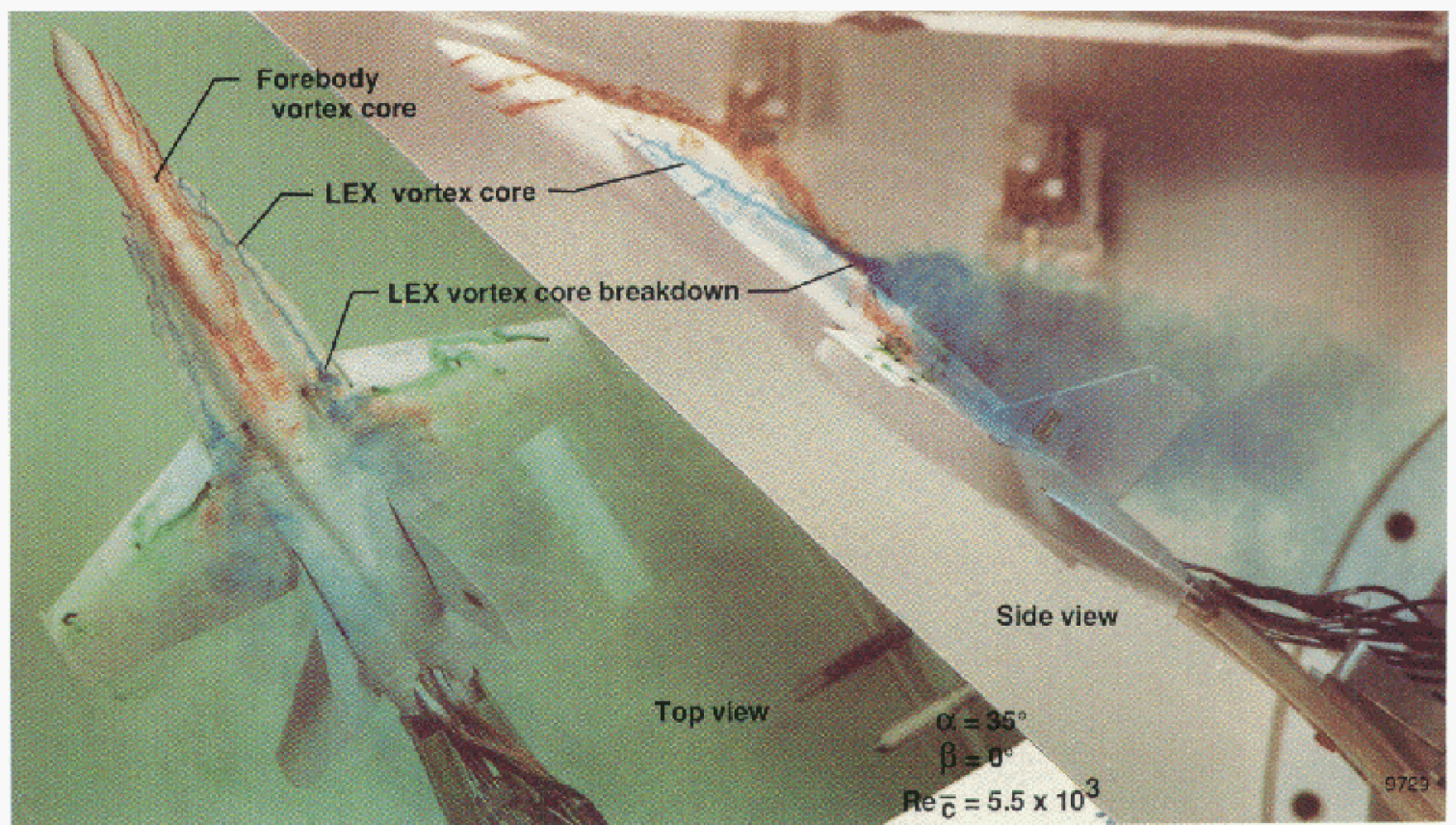

Figure 4. Vortex flow on 1/48-scale model of F-18 HARV in Ames-Dryden water tunnel, $\alpha=35^{\circ}$.

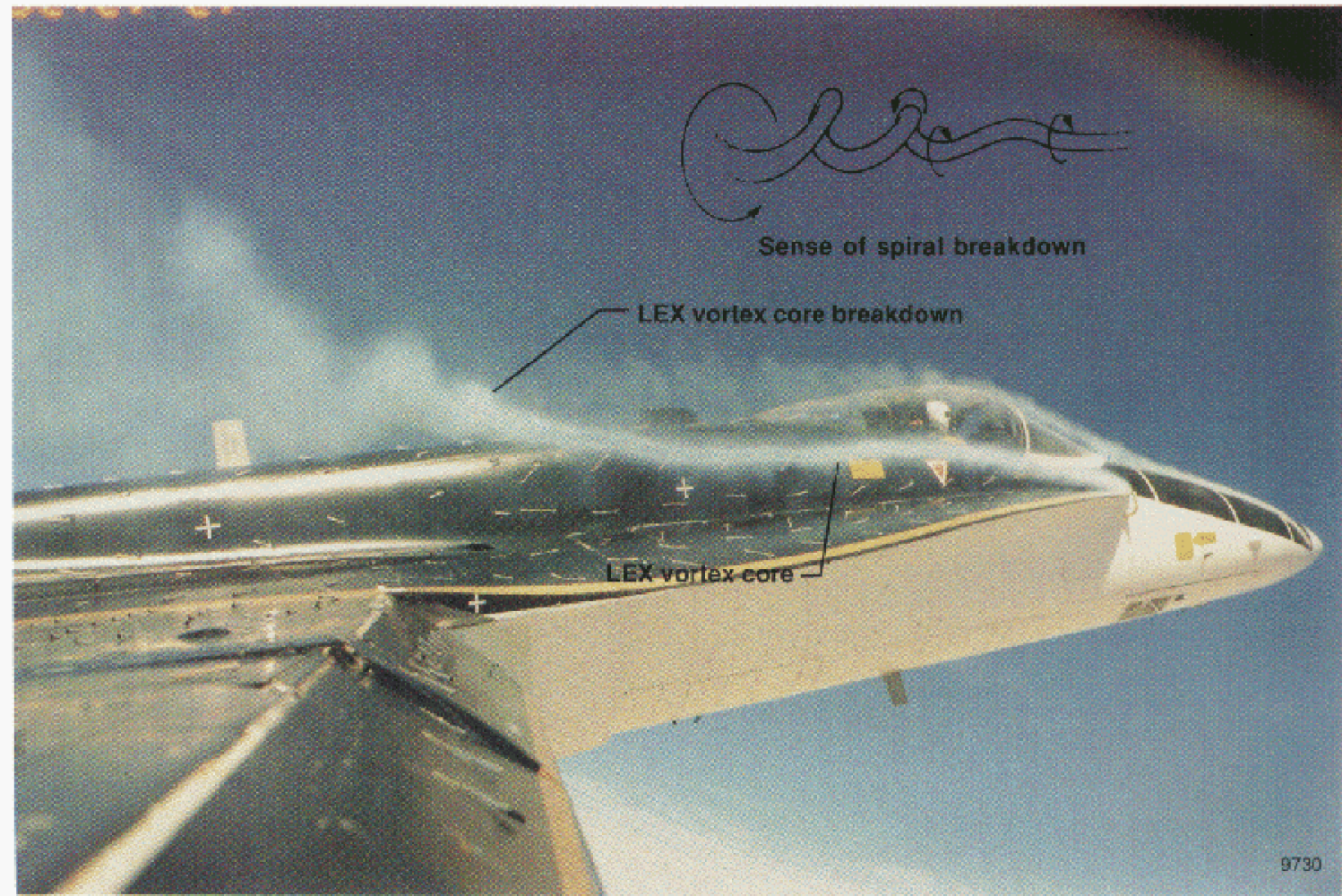

Figure 5. Flow visualization of LEX vortex core of F-18 HARV, wingtip view, $\alpha=25.0^{\circ}$ and $\beta=-1.4^{\circ}$. 


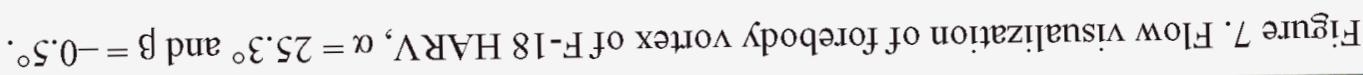

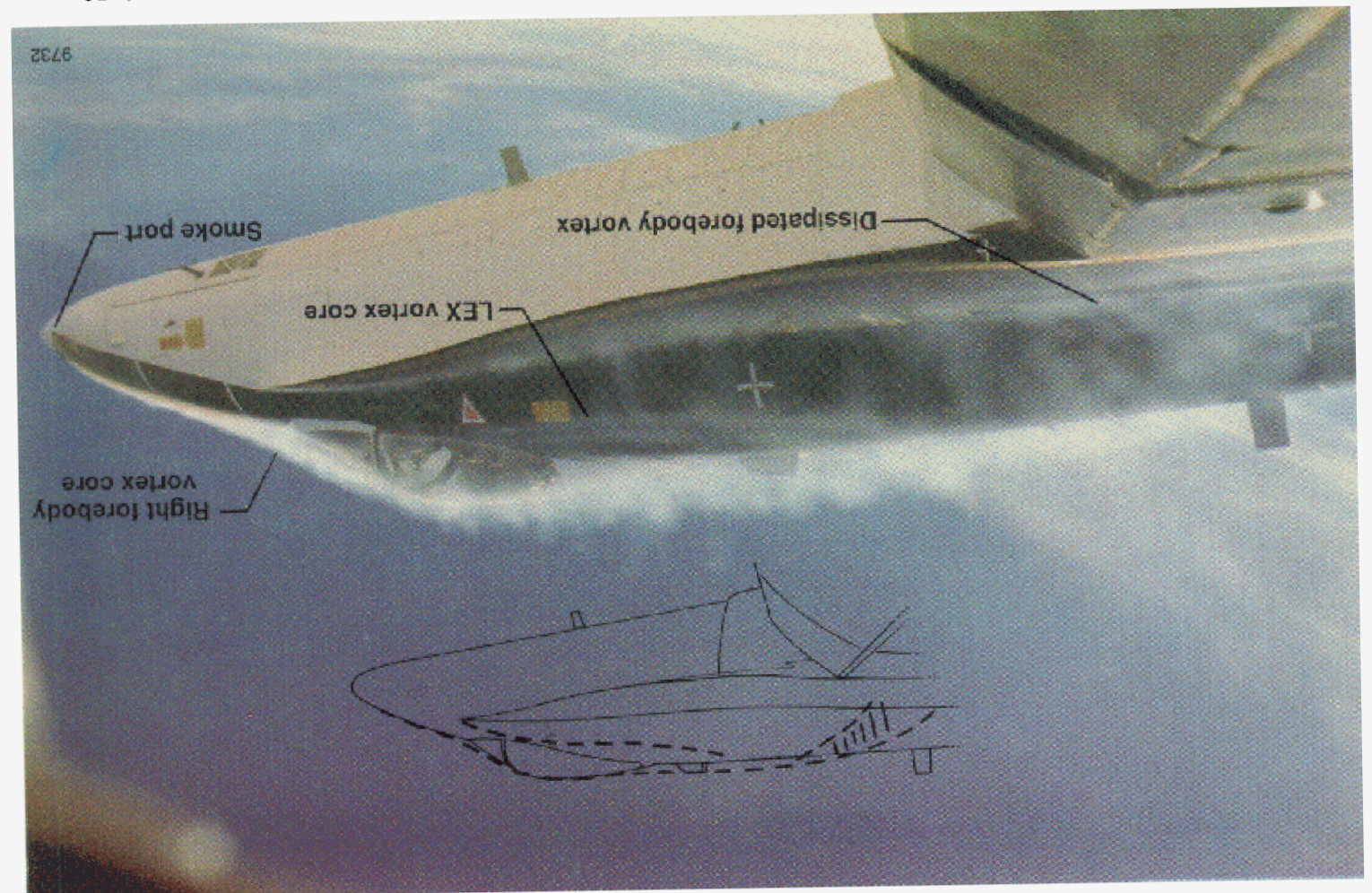

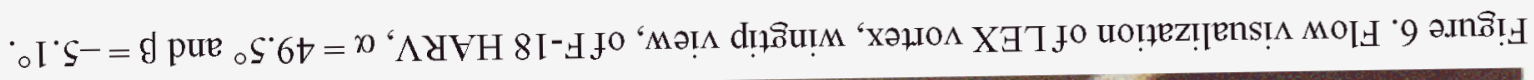

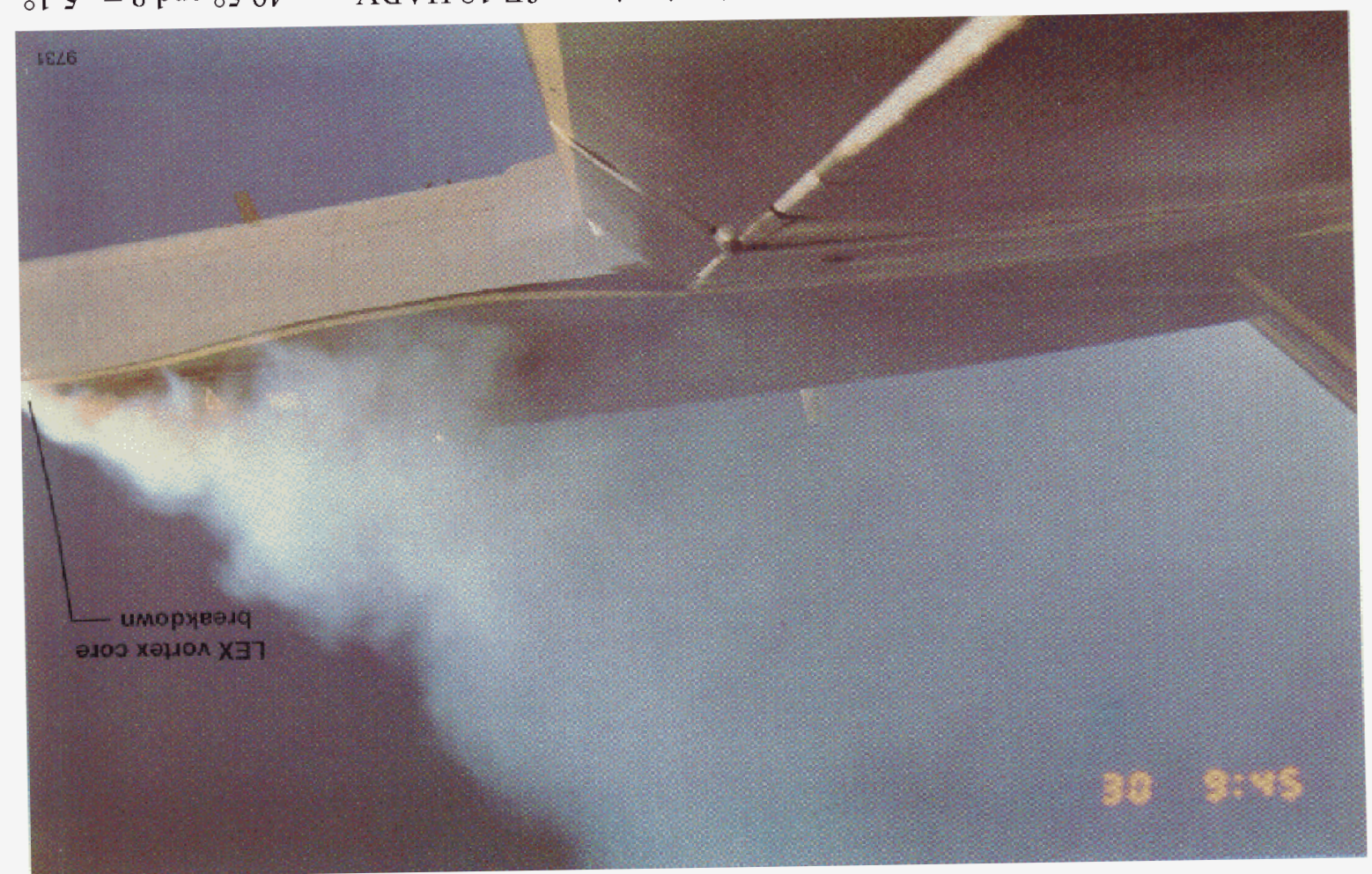




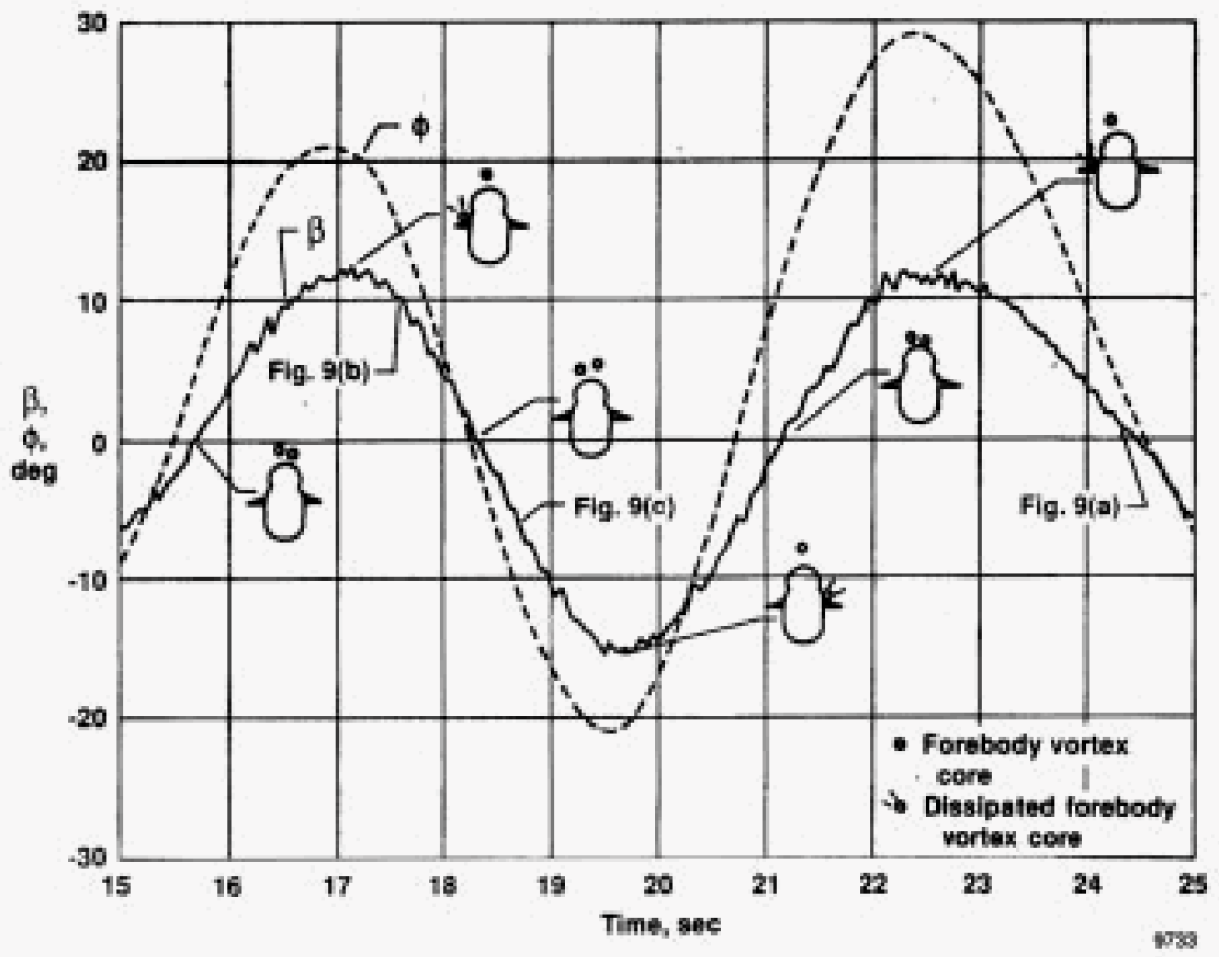

Figure 8. Time history of roll angle and angle of sideslip of F-18 HARV during wing rock, $\alpha \sim 45^{\circ}$, and forebody core positions at pilot's station.

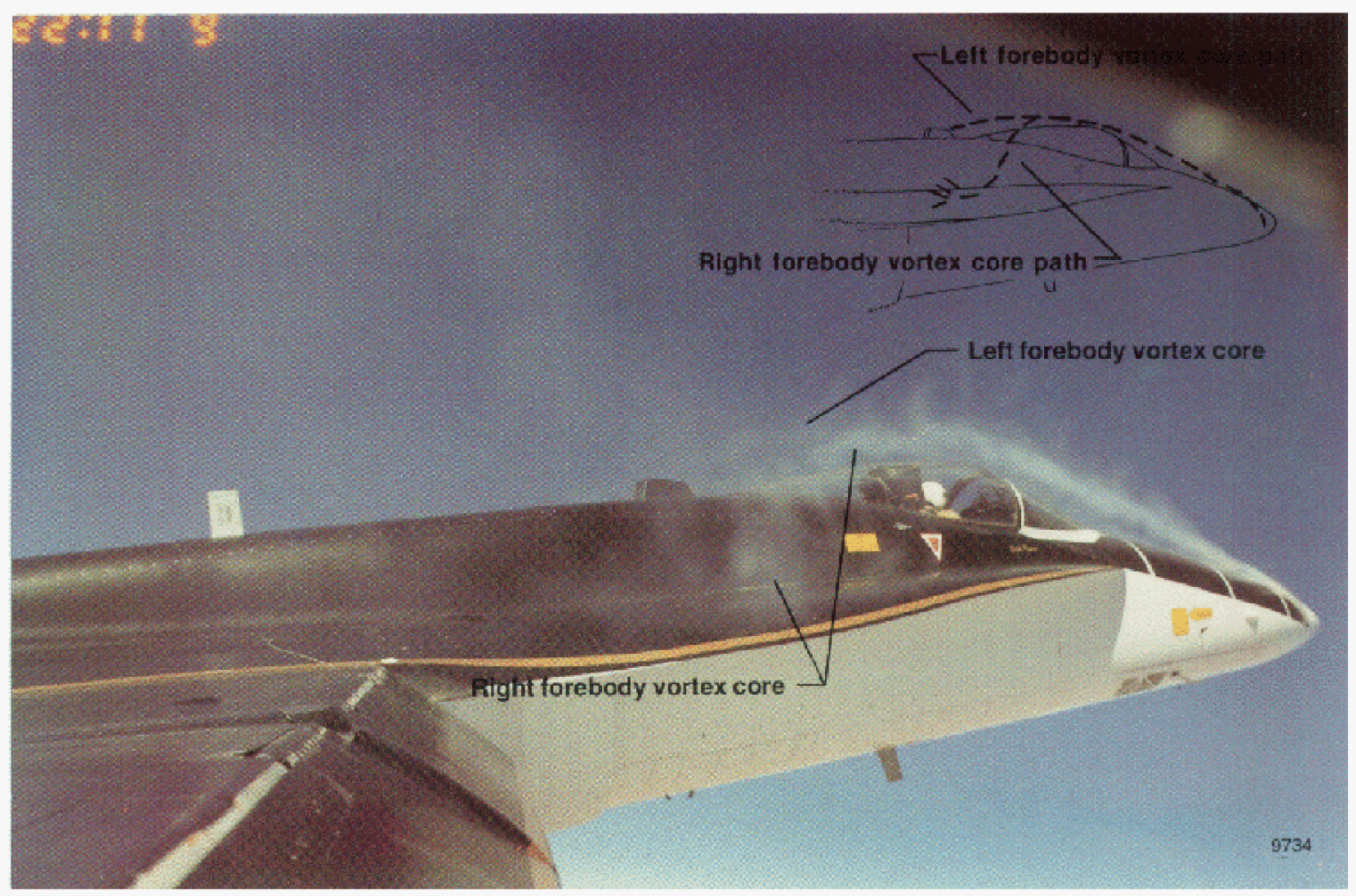

(a) $\alpha=42.5^{\circ}, \beta=-0.5^{\circ}$.

Figure 9. Flow visualization of forebody vortex cores of F-18 HARV during wing rock, $\alpha \sim 45^{\circ}$. 


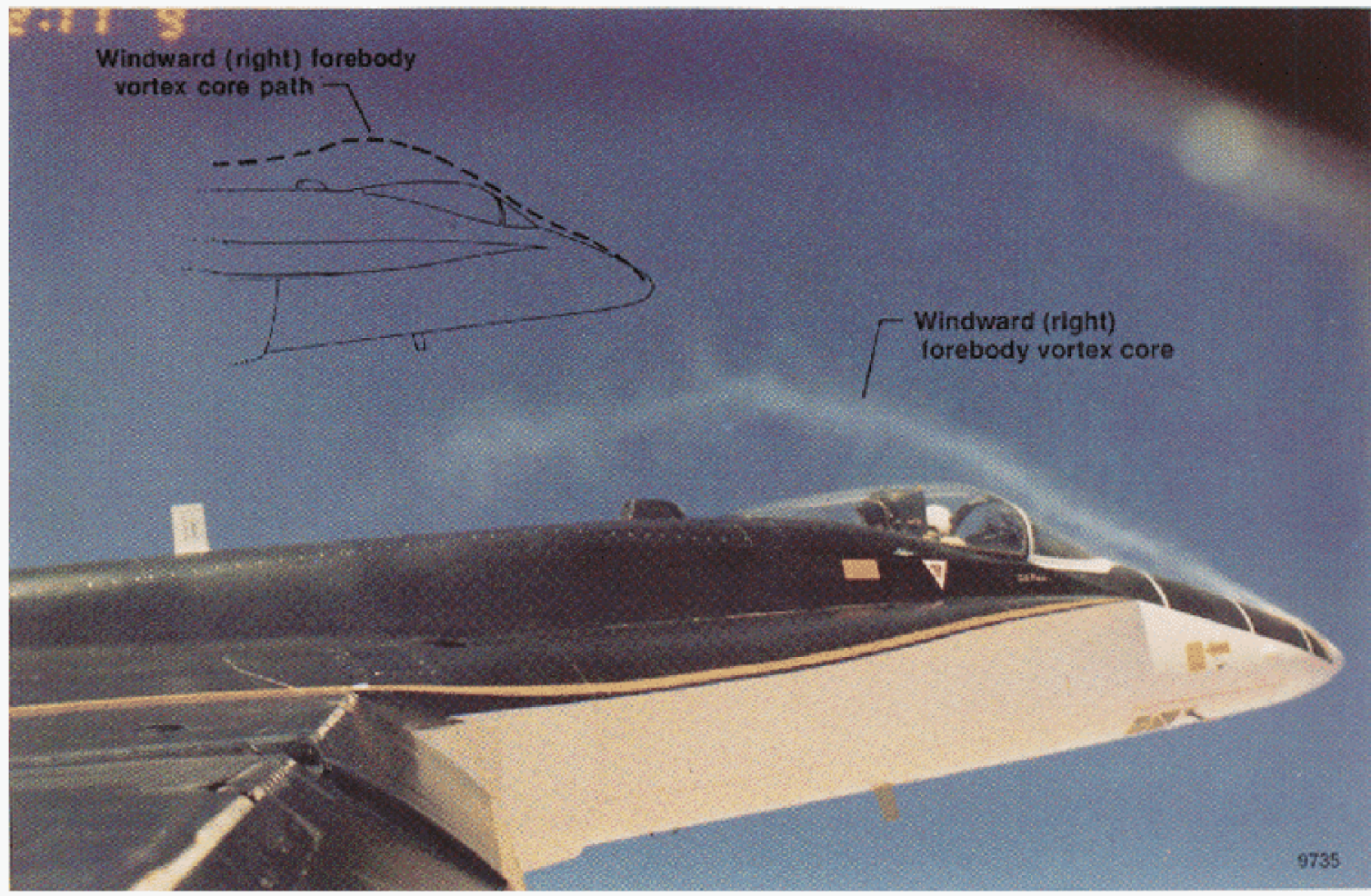

(b) $\alpha=42.8^{\circ}, \beta=9.0^{\circ}$.

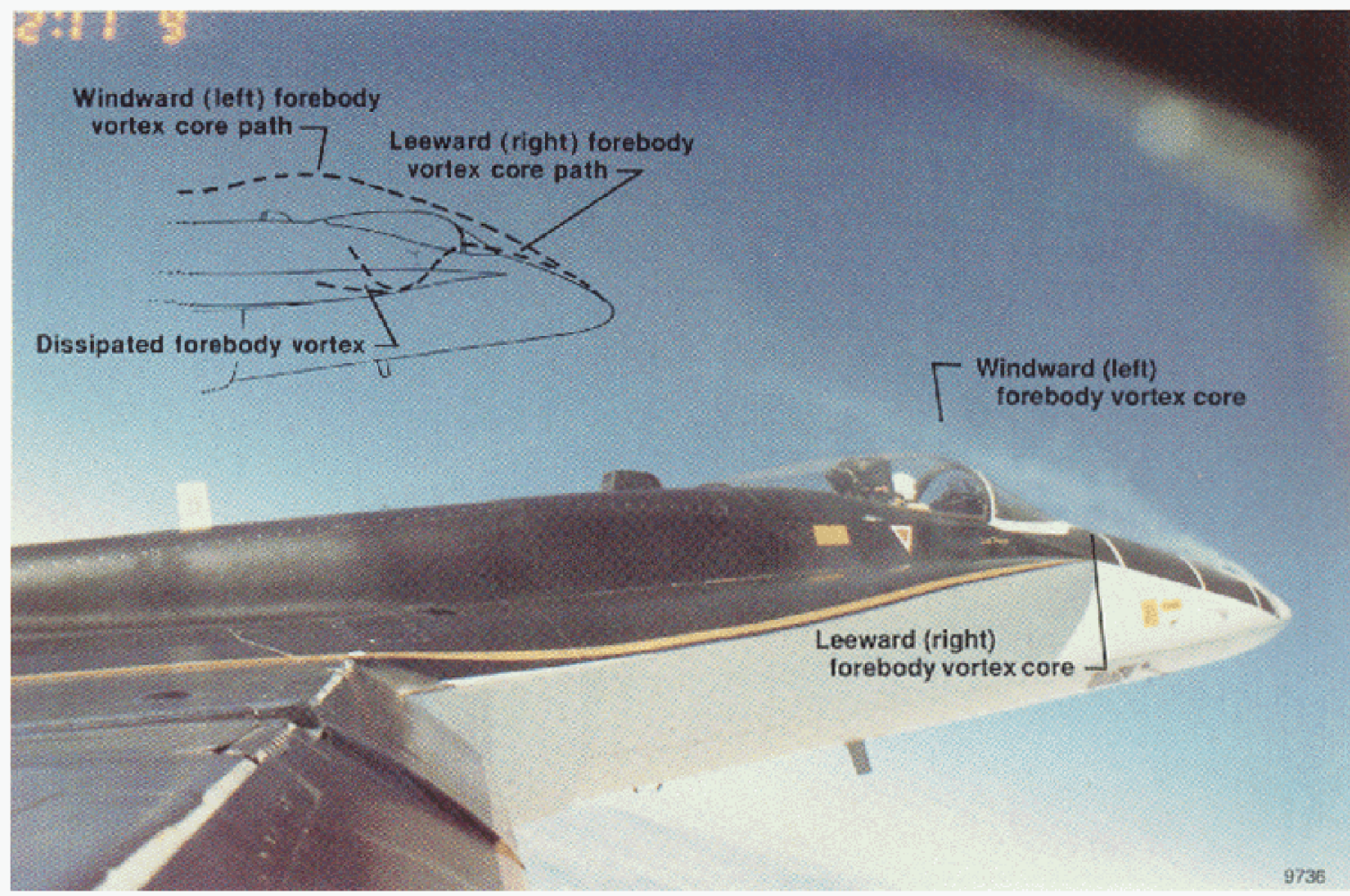

(c) $\alpha=45.1^{\circ}, \beta=-5.5^{\circ}$.

Figure 9. Concluded. 


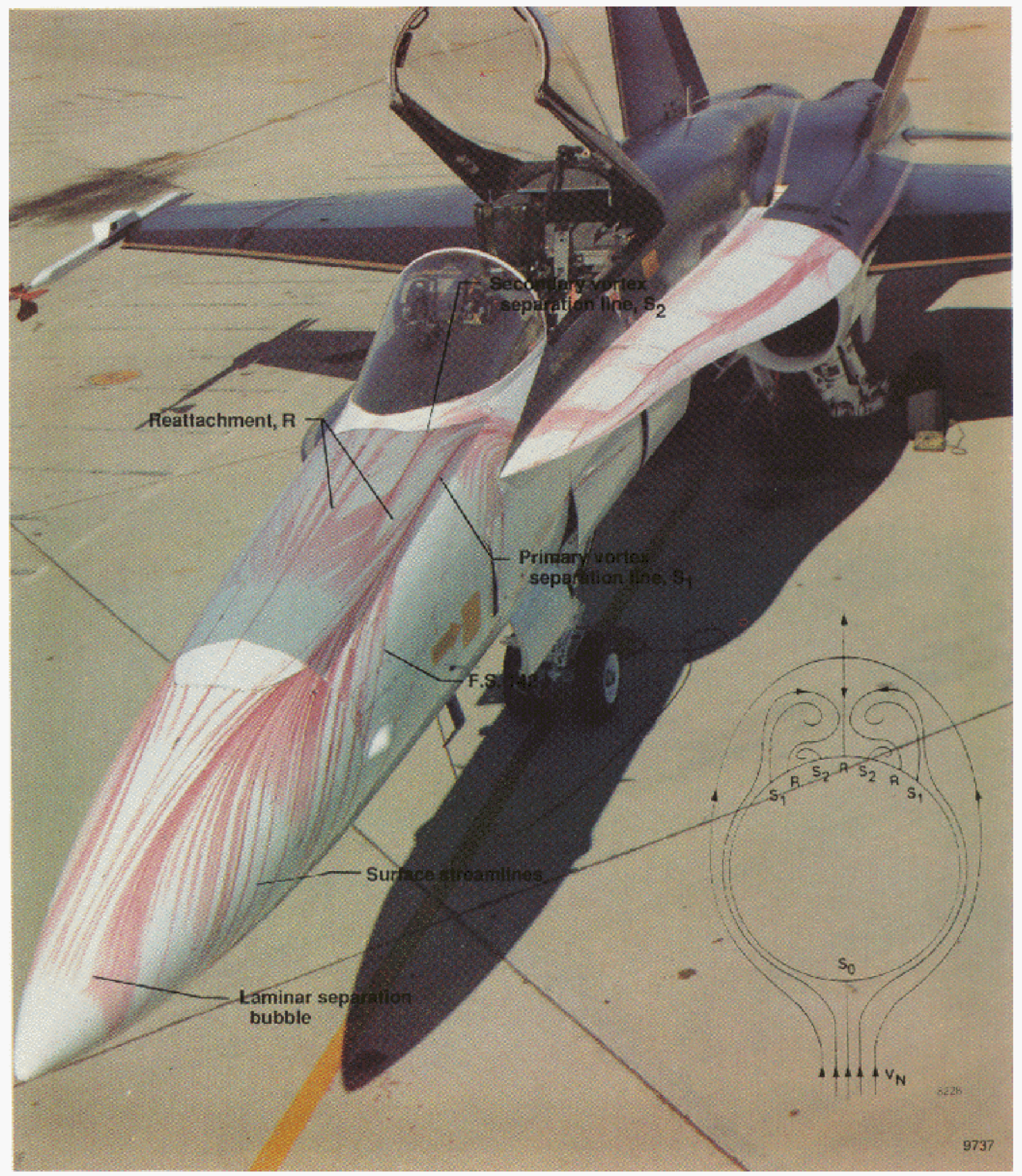

(a) $1 / 4$ view.

Figure 10. Surface flow visualization on forebody of F-18 HARV, $\alpha=26^{\circ}$. 


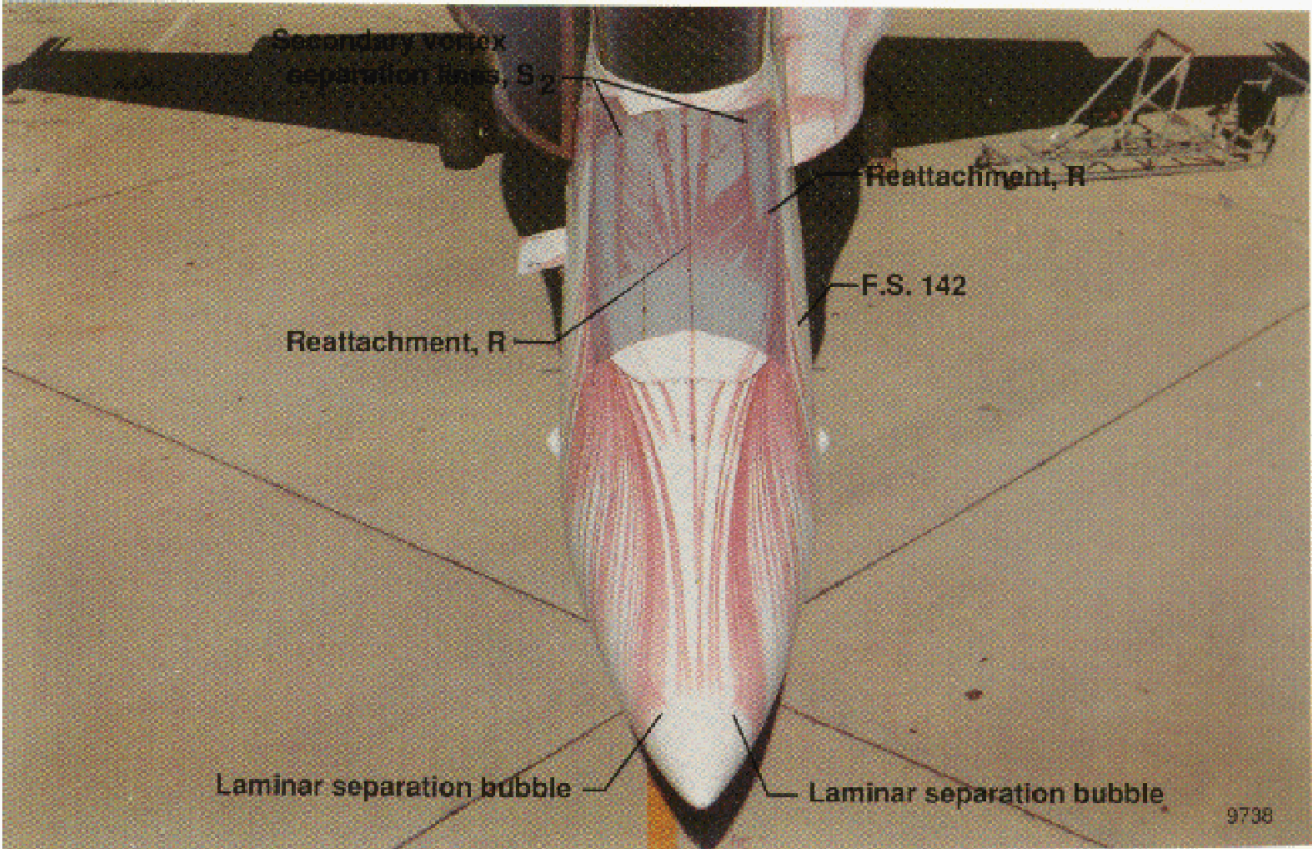

(b) Head-on view.

Figure 10. Concluded.
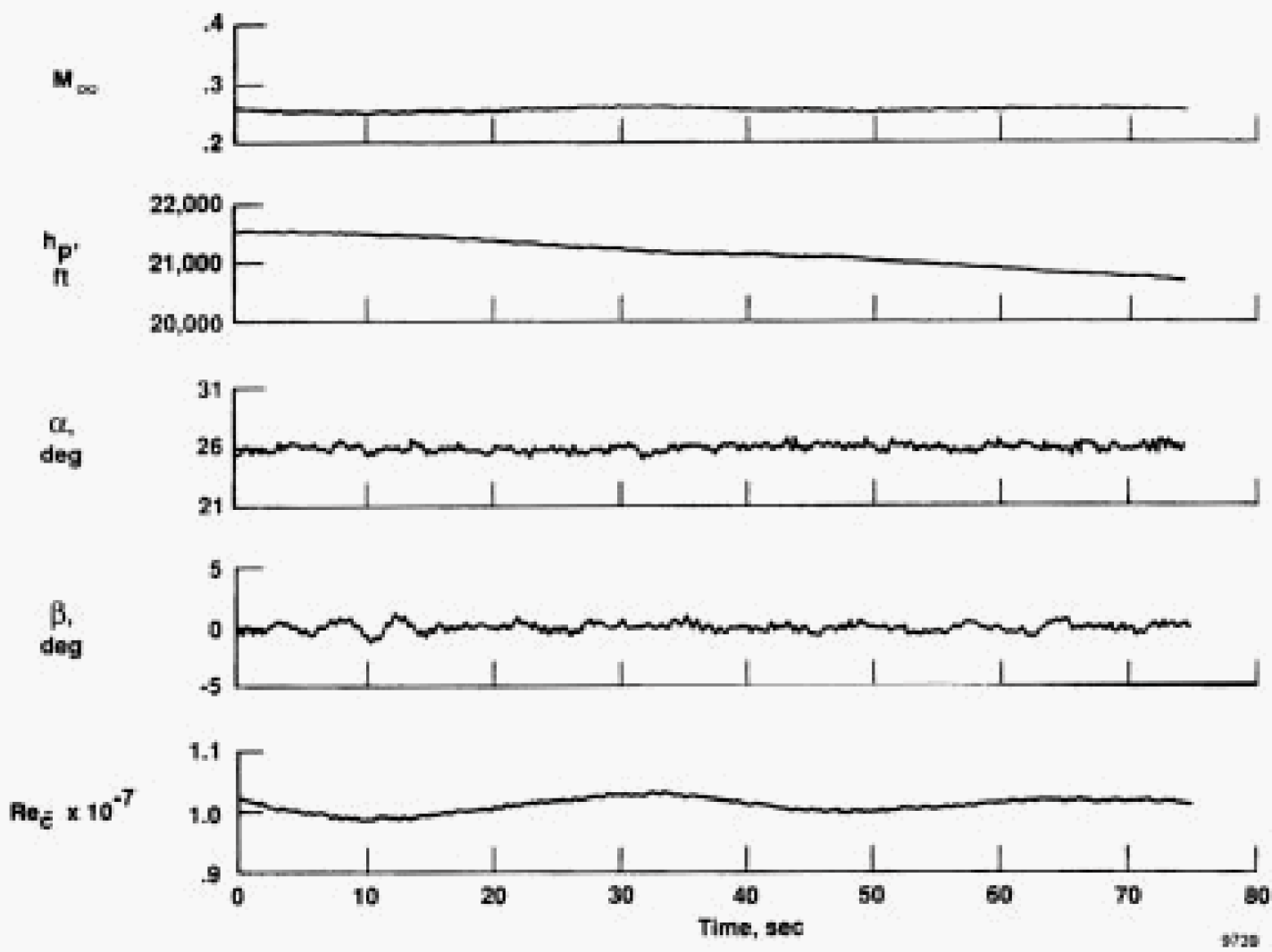

Figure 11. Time history of F-18 HARV during $\alpha=26^{\circ}$ surface flow visualization. 


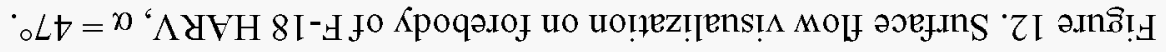

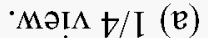

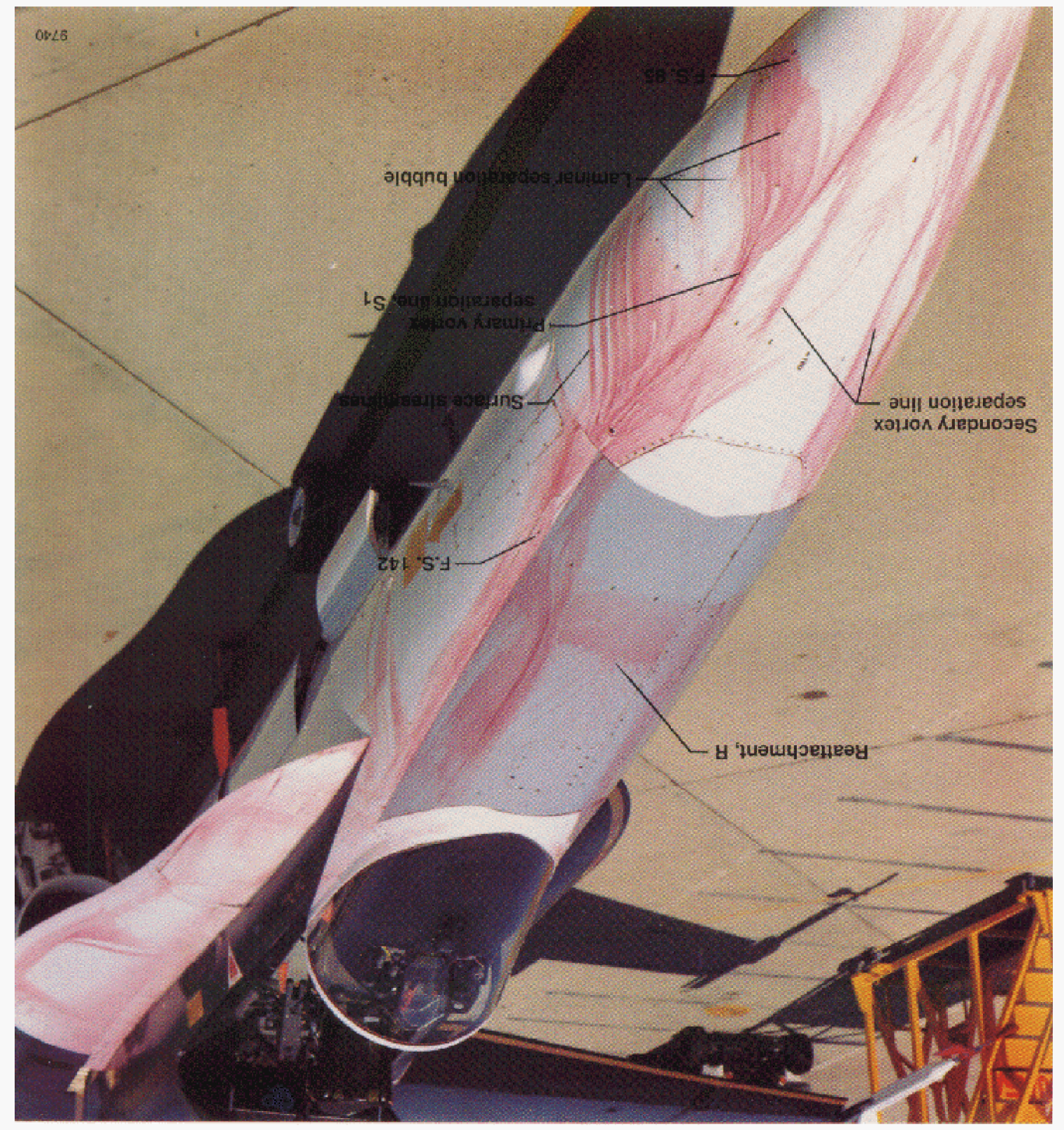




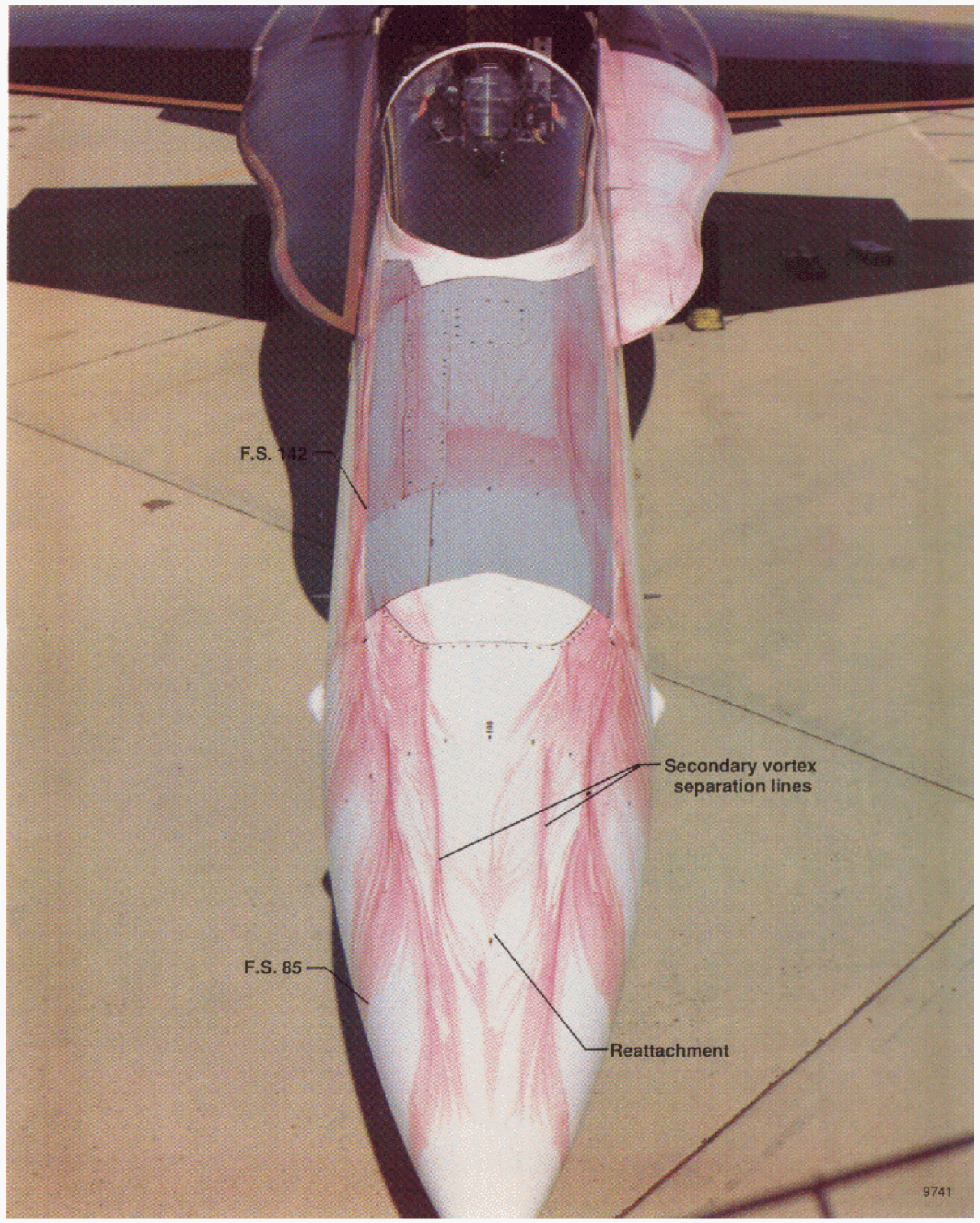

(b) Head-on view.

Figure 12. Concluded. 

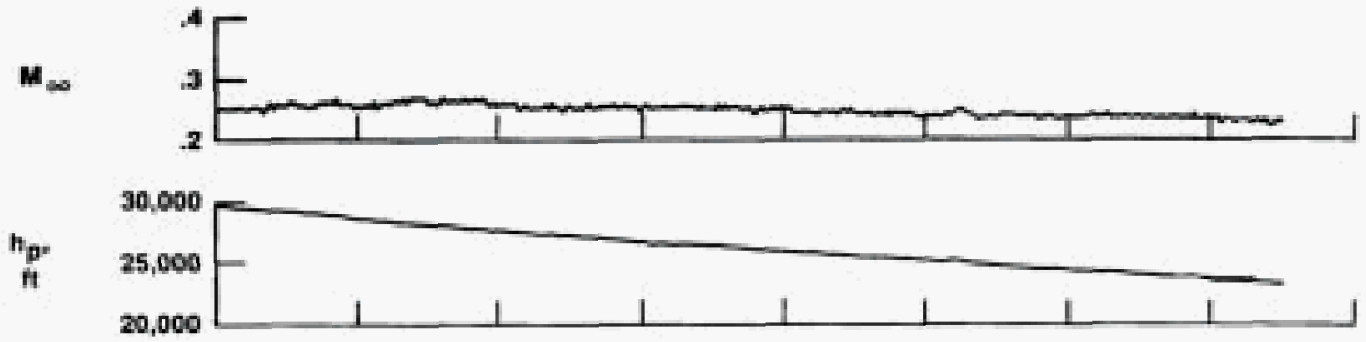

deg

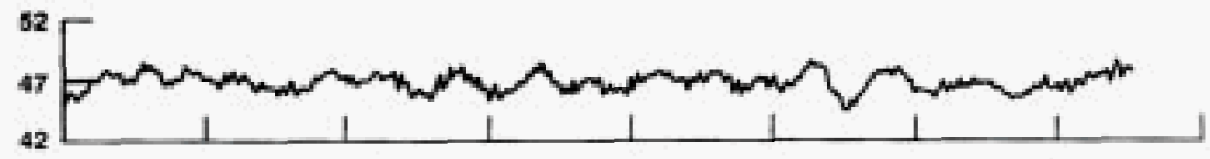

A,
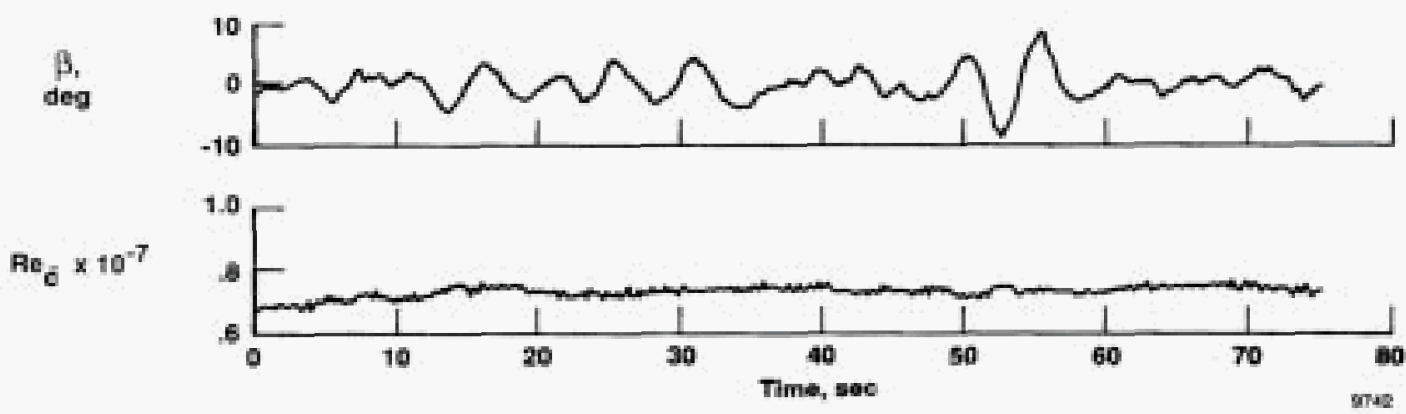

Figure 13 . Time history during $\alpha=47^{\circ}$ surface flow visualization.

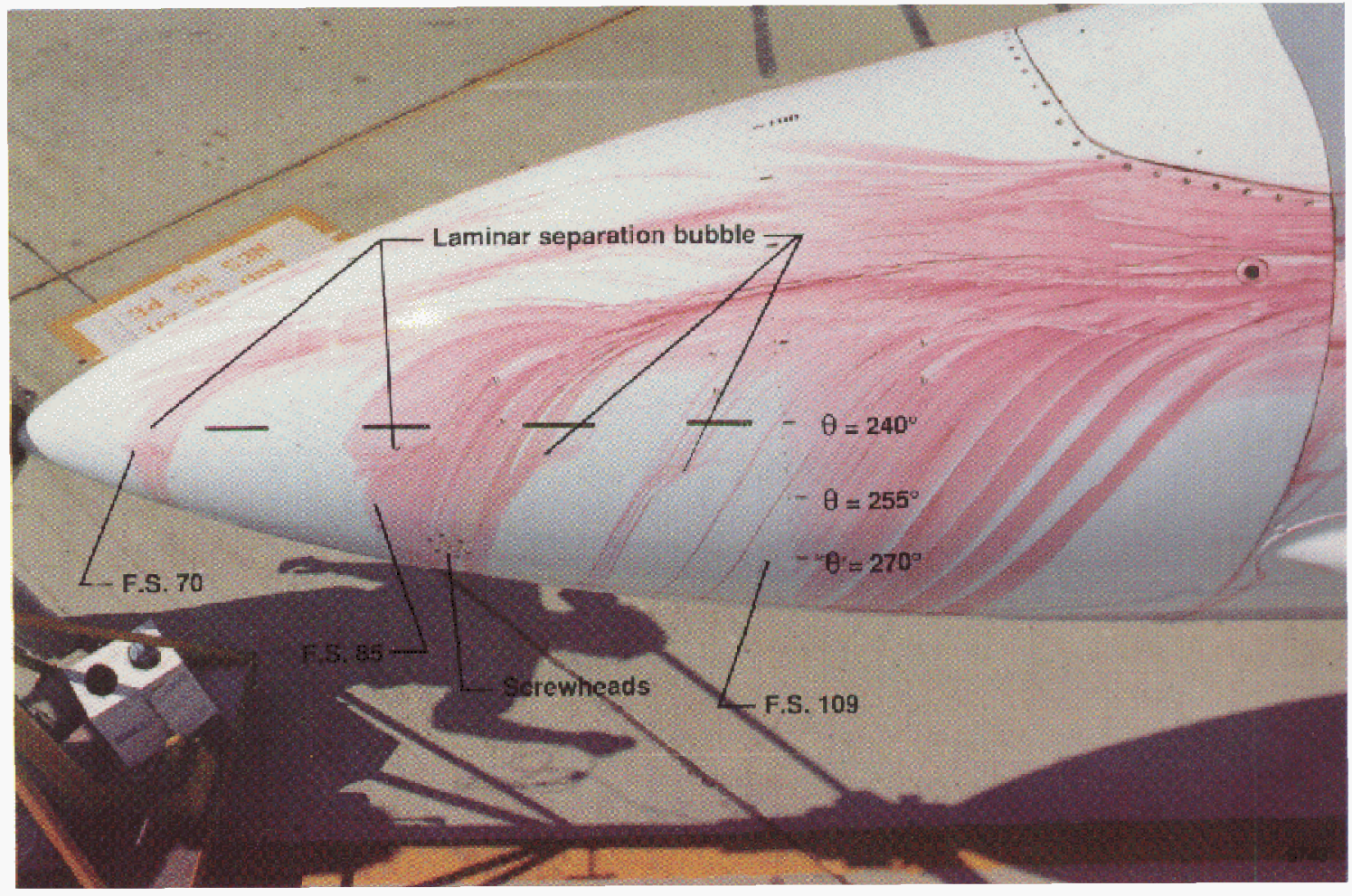

Figure 14. Closeup of nose cone of F-18 HARV, $\alpha=47^{\circ}$. 


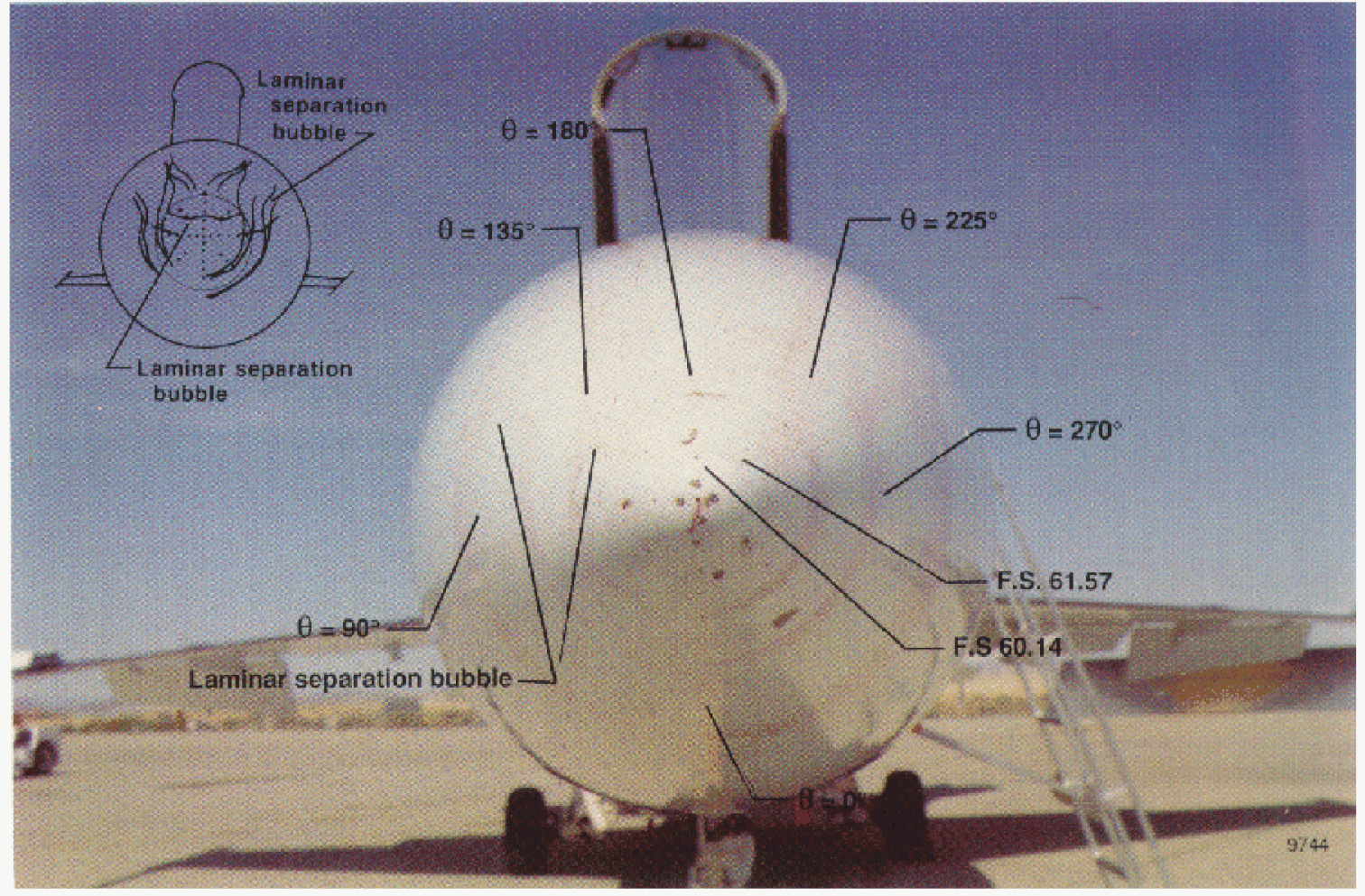

(a) Head-on view.

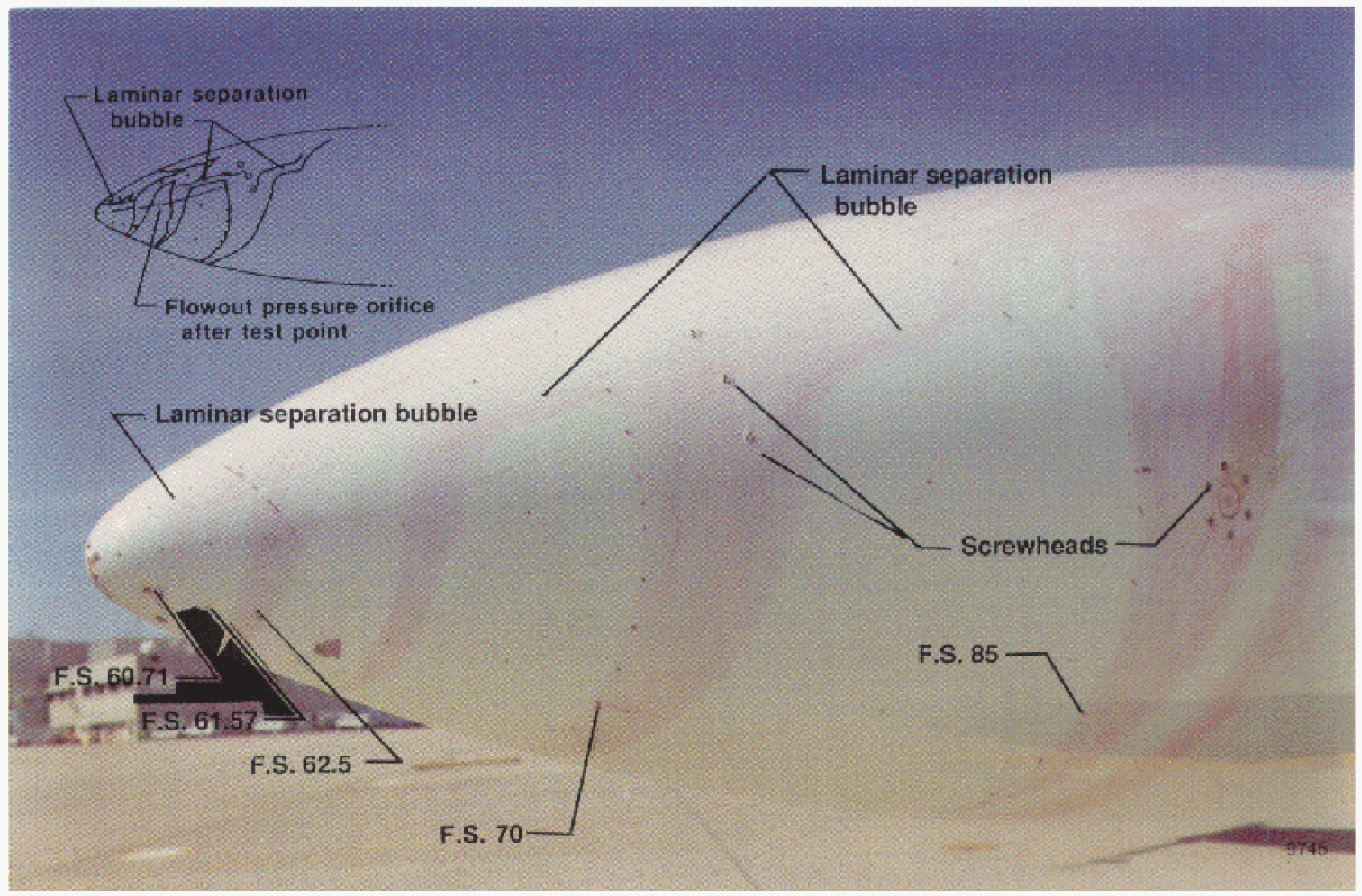

(b) $1 / 4$ view.

Figure 15. Closeup of nose cone of F-18 HARV with emitted fluid out FADS orifices, $\alpha=49^{\circ}$. 


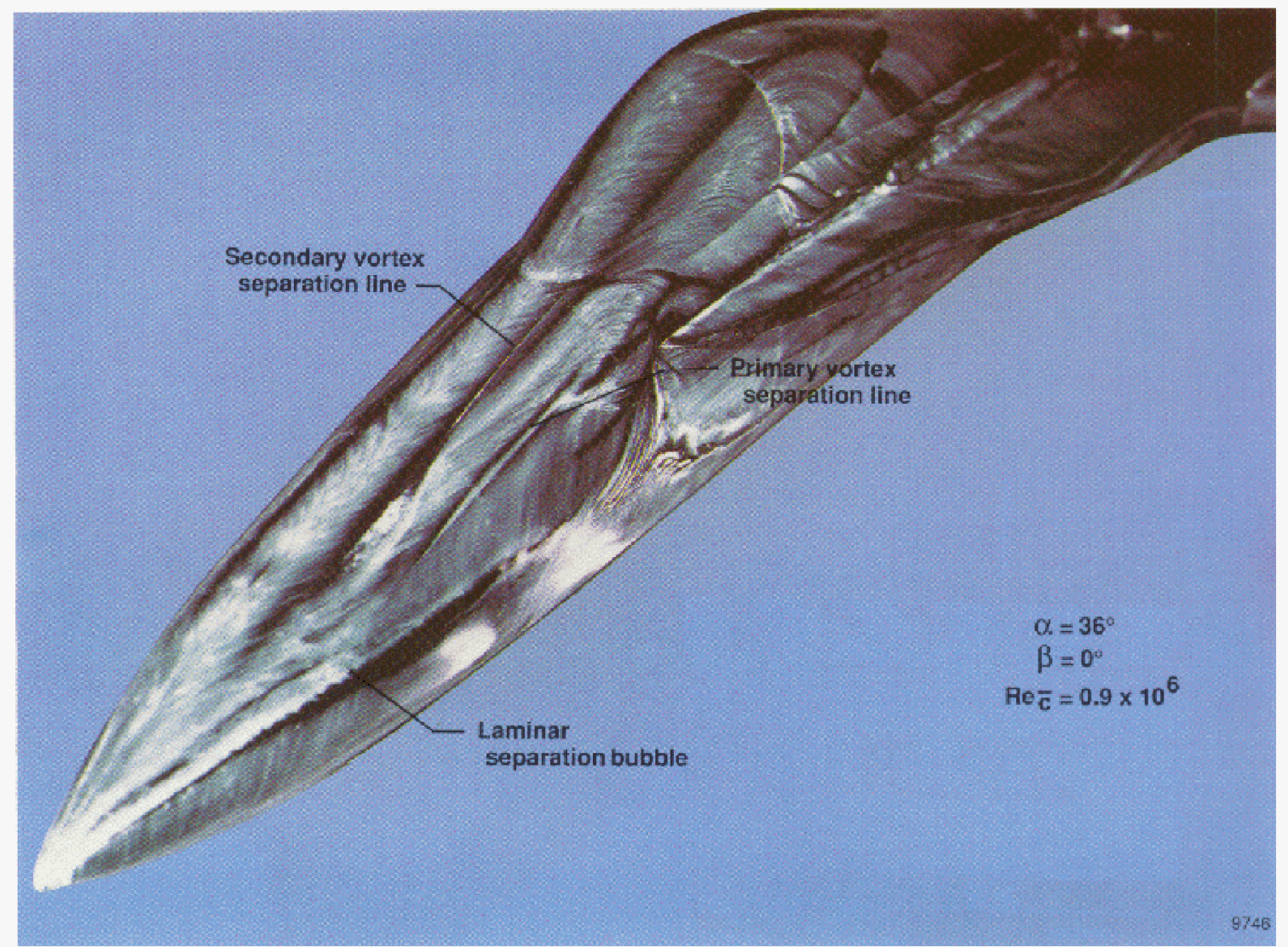

(a) Oil flow visualization of surface streamlines, 0.16-scale model of F-18 airplace, Langley Research Center 14- by 22-Foot Subsonic Tunnel.

Figure 16. Wind-tunnel results on F-18 airplane, $\alpha=36^{\circ}$. 

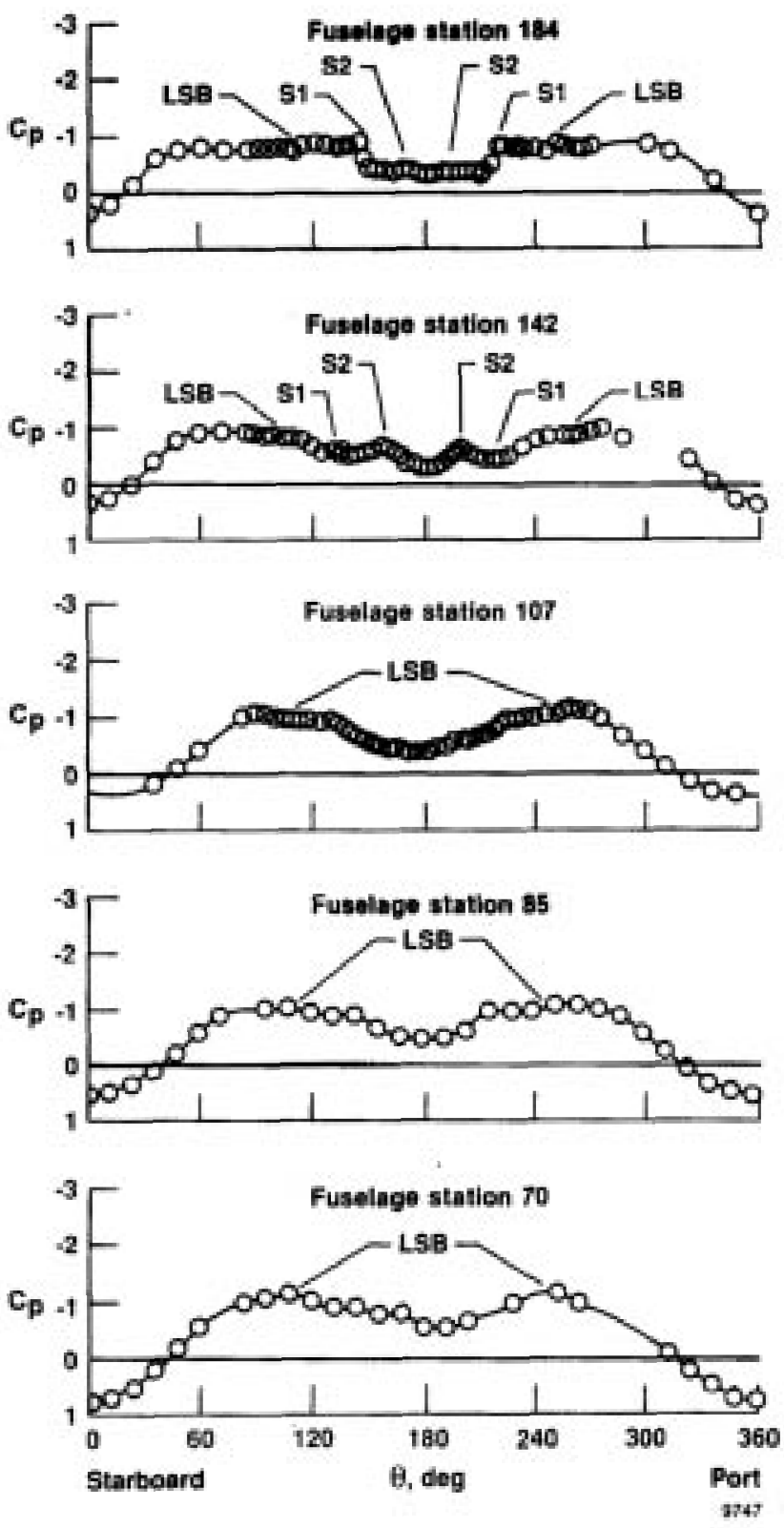

(b) Pressure distribution on 0.16-scale model of F-18 airplane forebody.

Figure 16. Concluded. 


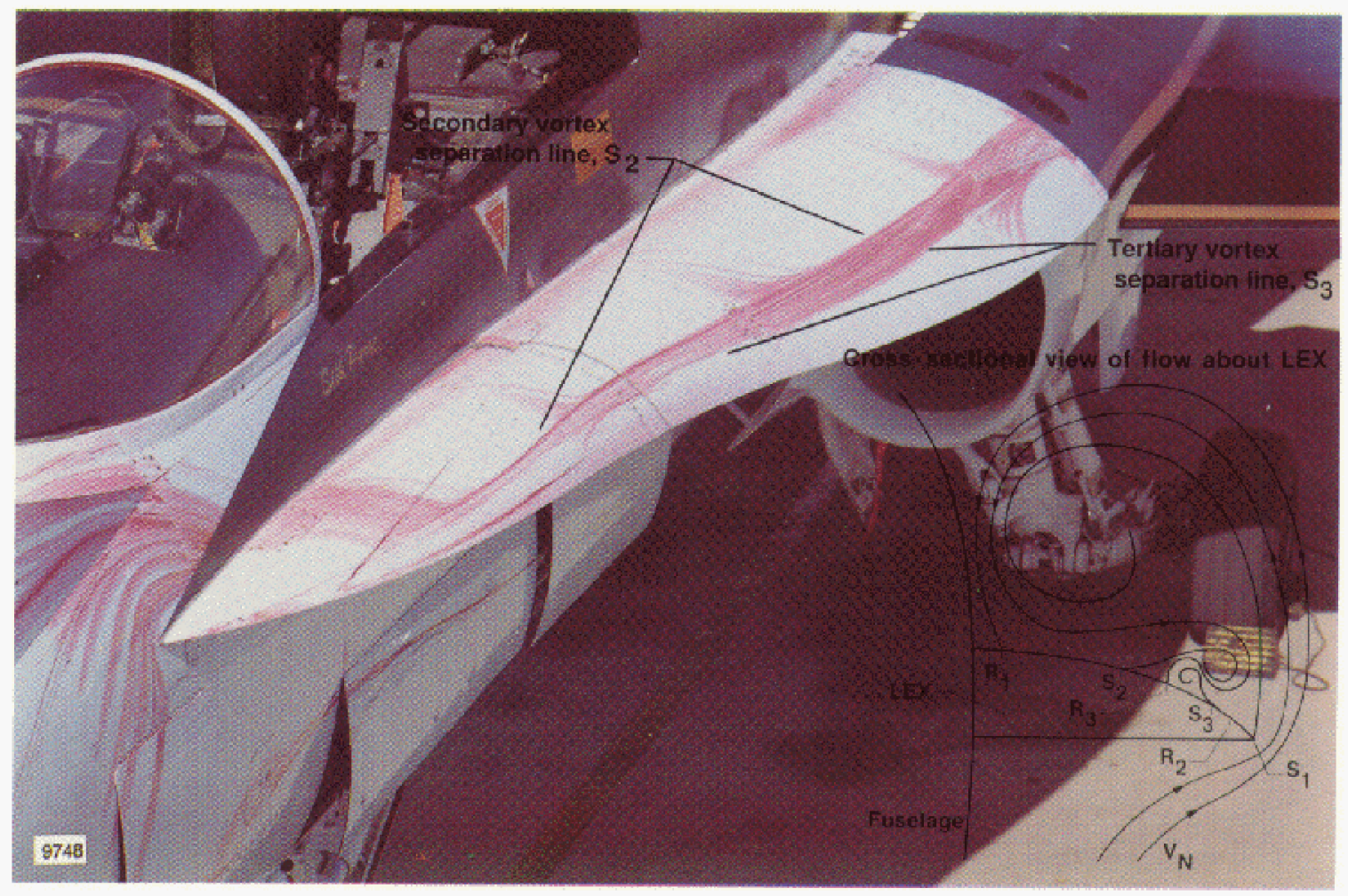

(a) Overall view.

Figure 17. Surface flow visualization on left LEX of F-18 HARV, $\alpha=26^{\circ}$. 


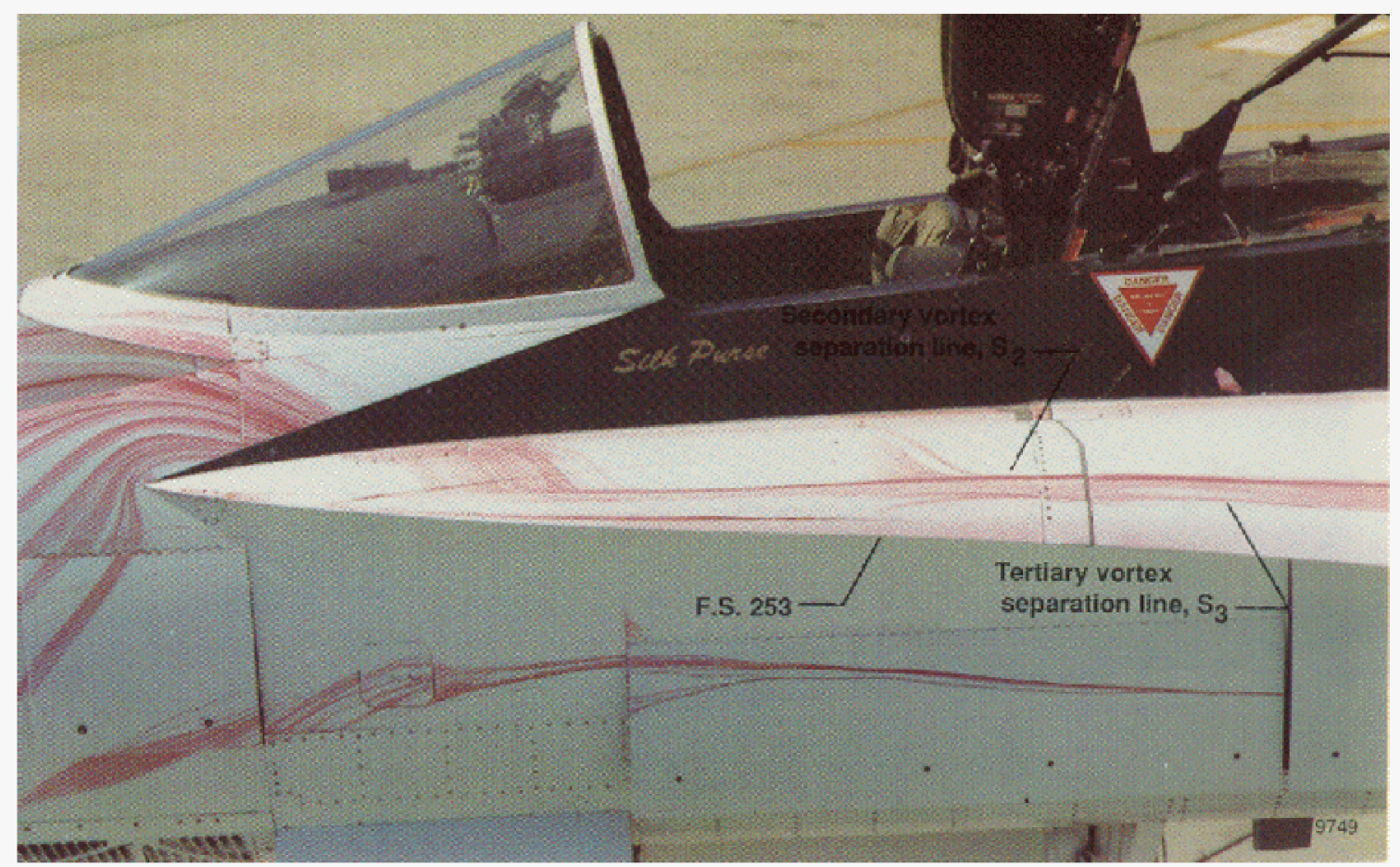

(b) Closeup view, F.S. 253.

Figure 17. Continued. 


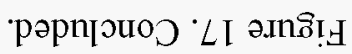

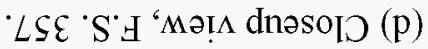

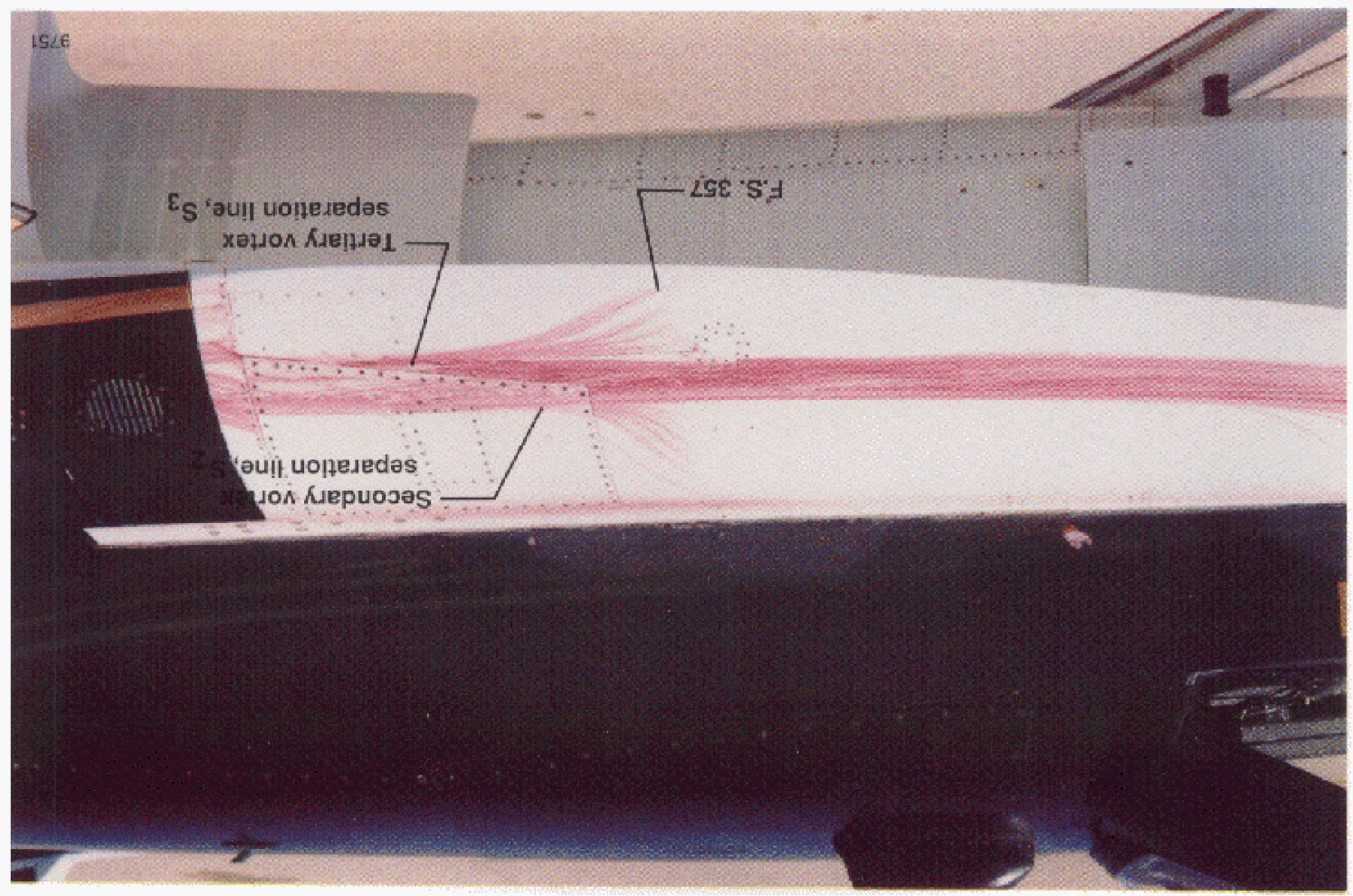

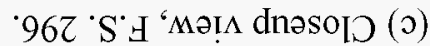

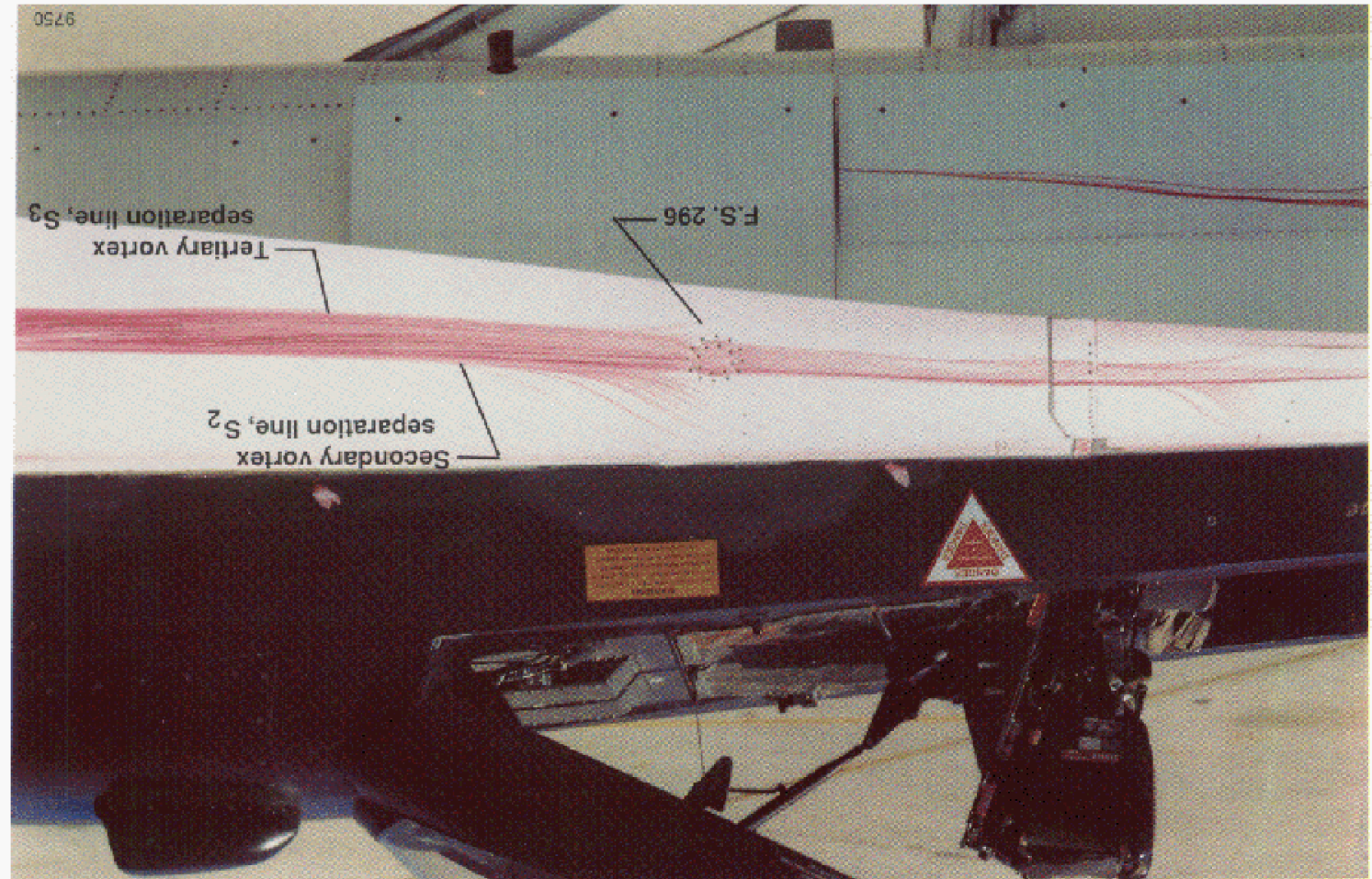




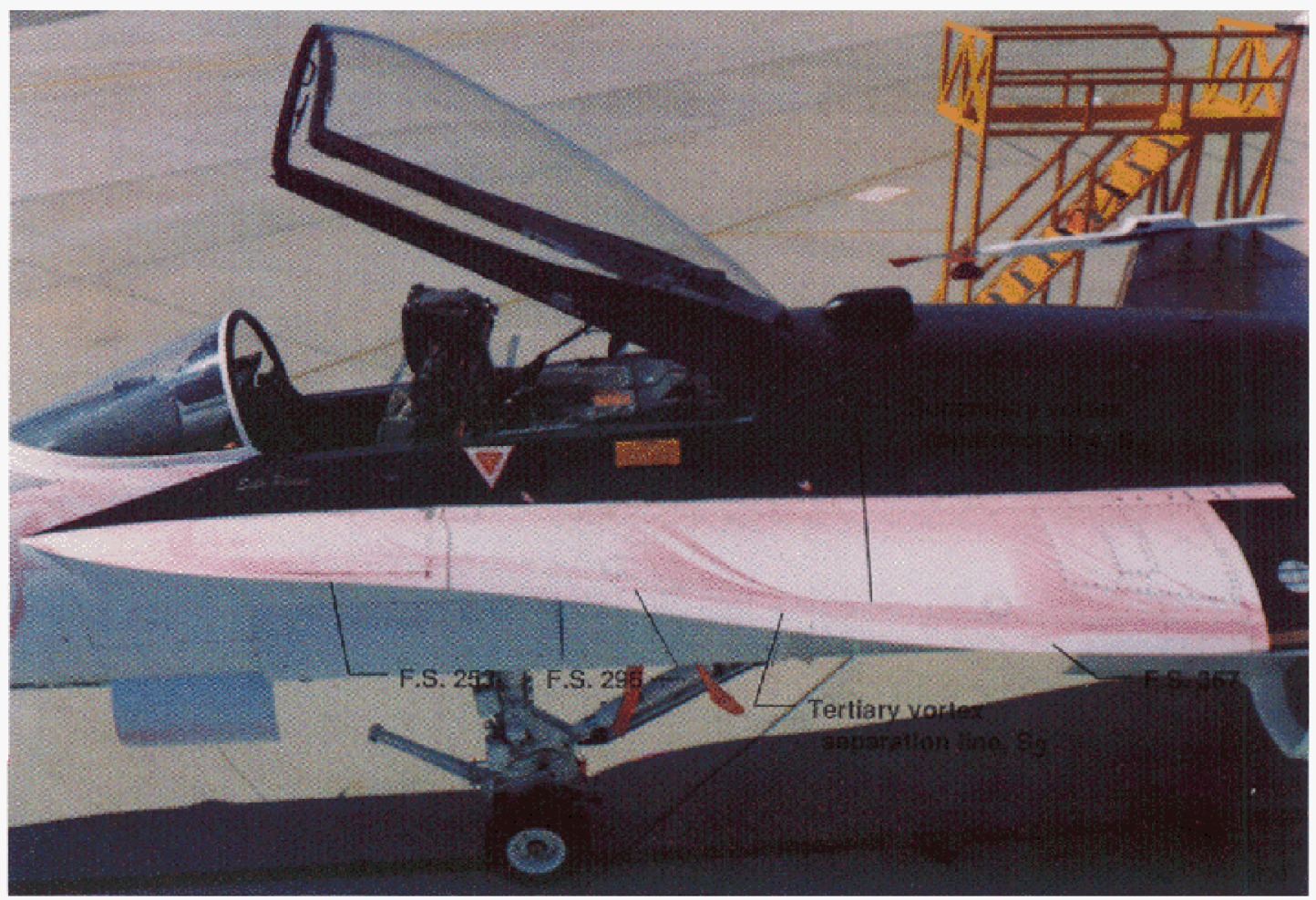

(a) Overall view.

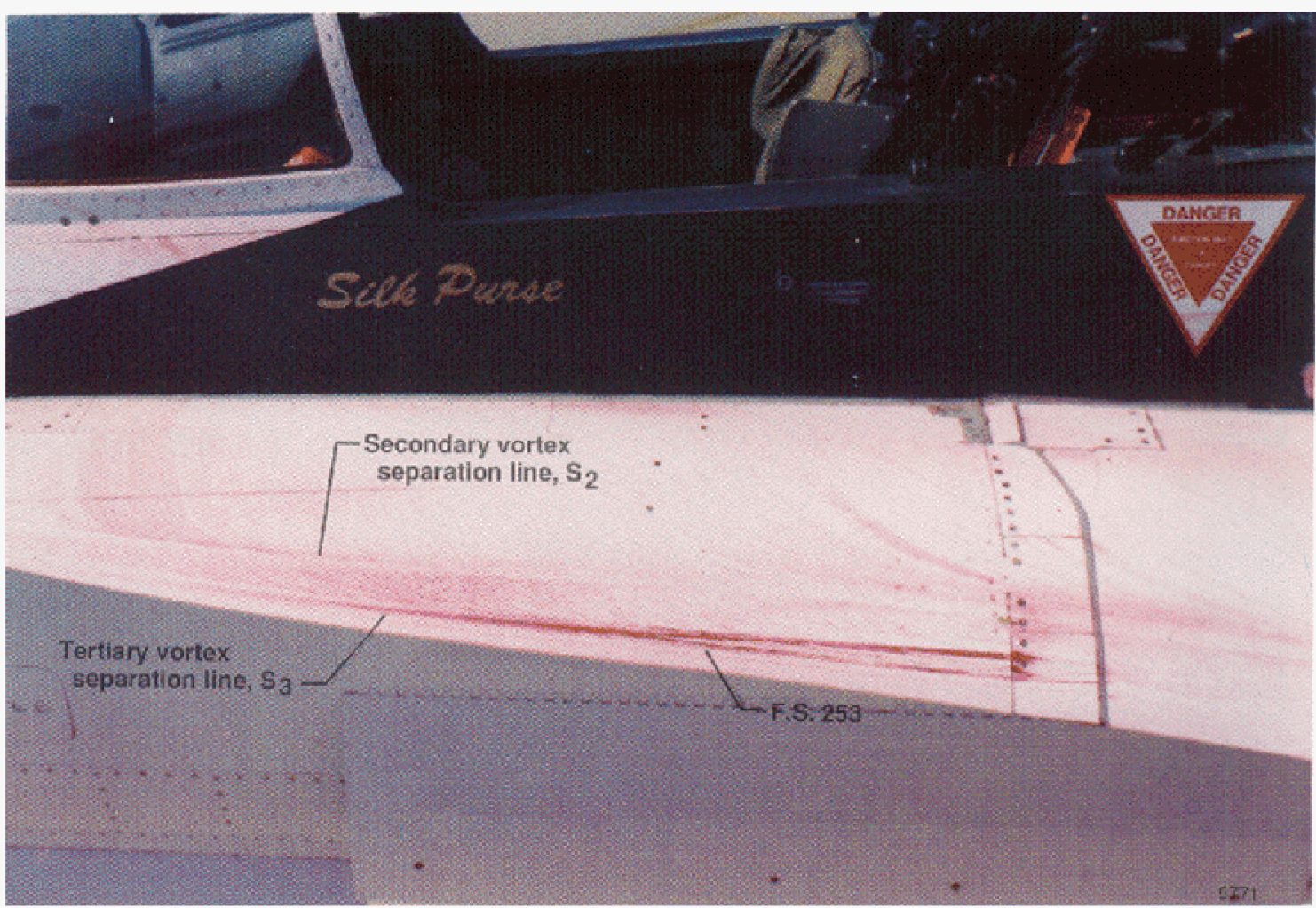

(b) Closeup view, F.S. 253.

Figure 18. Surface flow visualization on left LEX of F-18 HARV, $\alpha \sim 47^{\circ}$. 


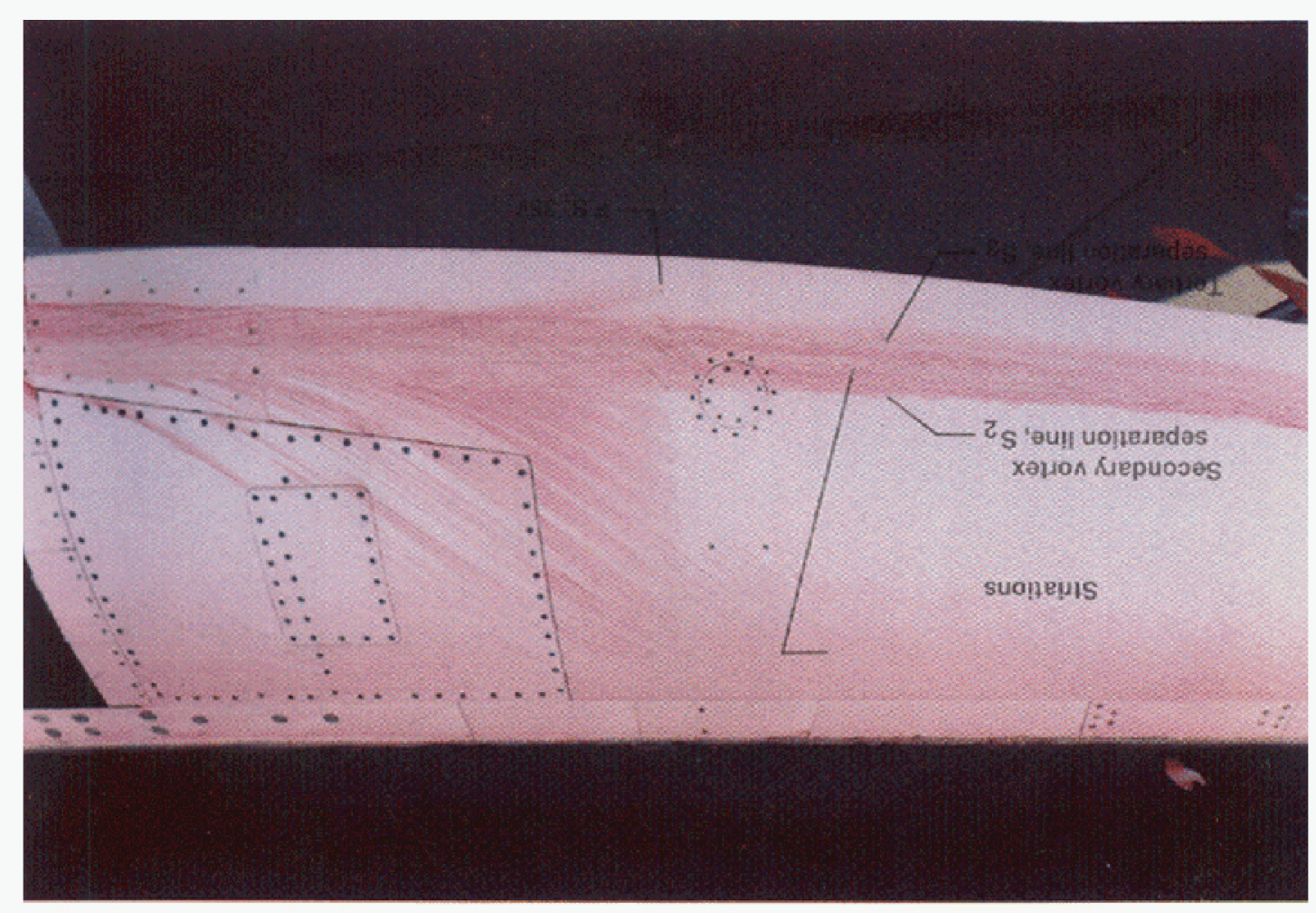

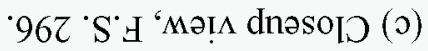

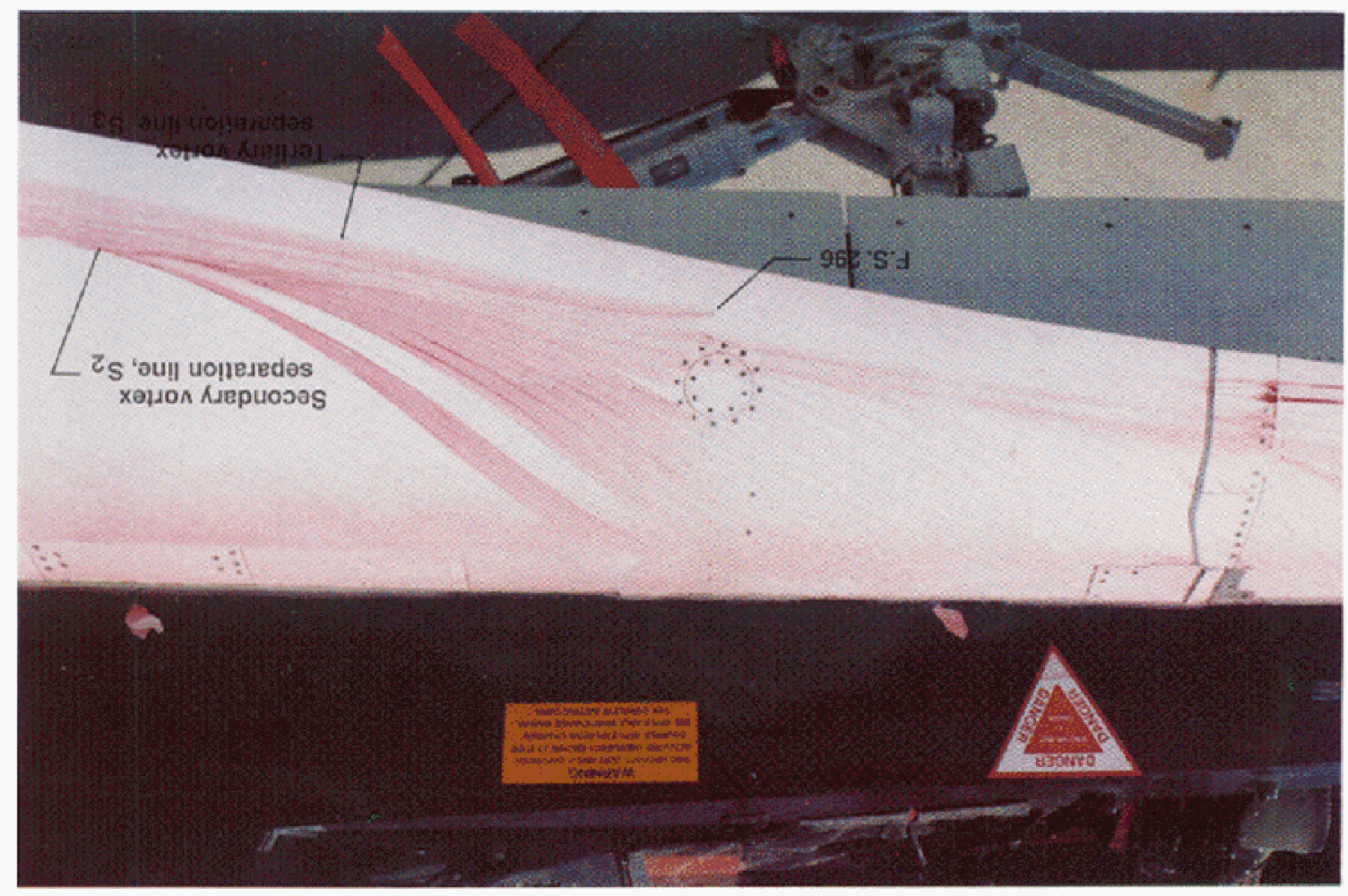




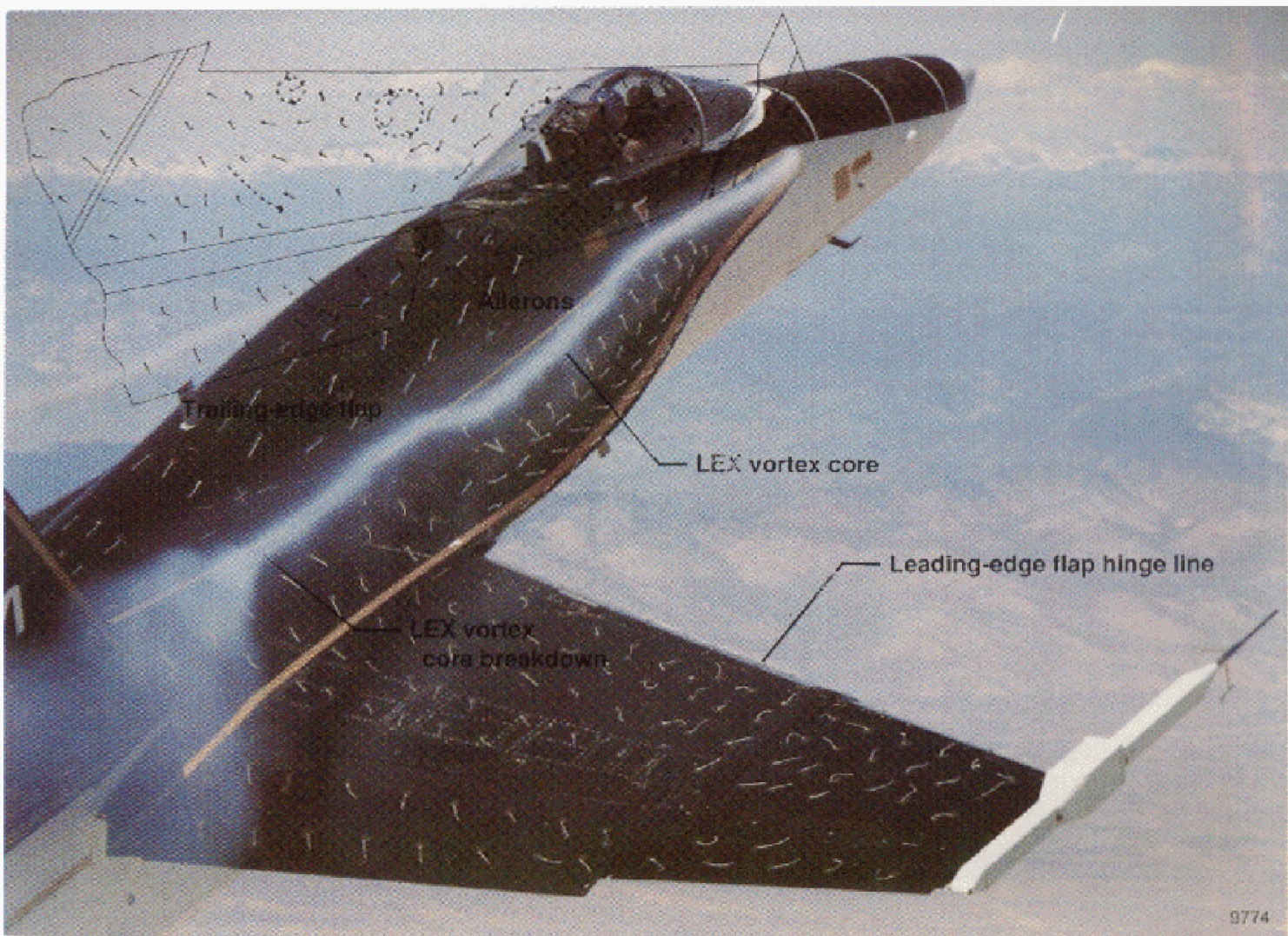

(a) View from chase aircraft, $\alpha \sim 20^{\circ}$.

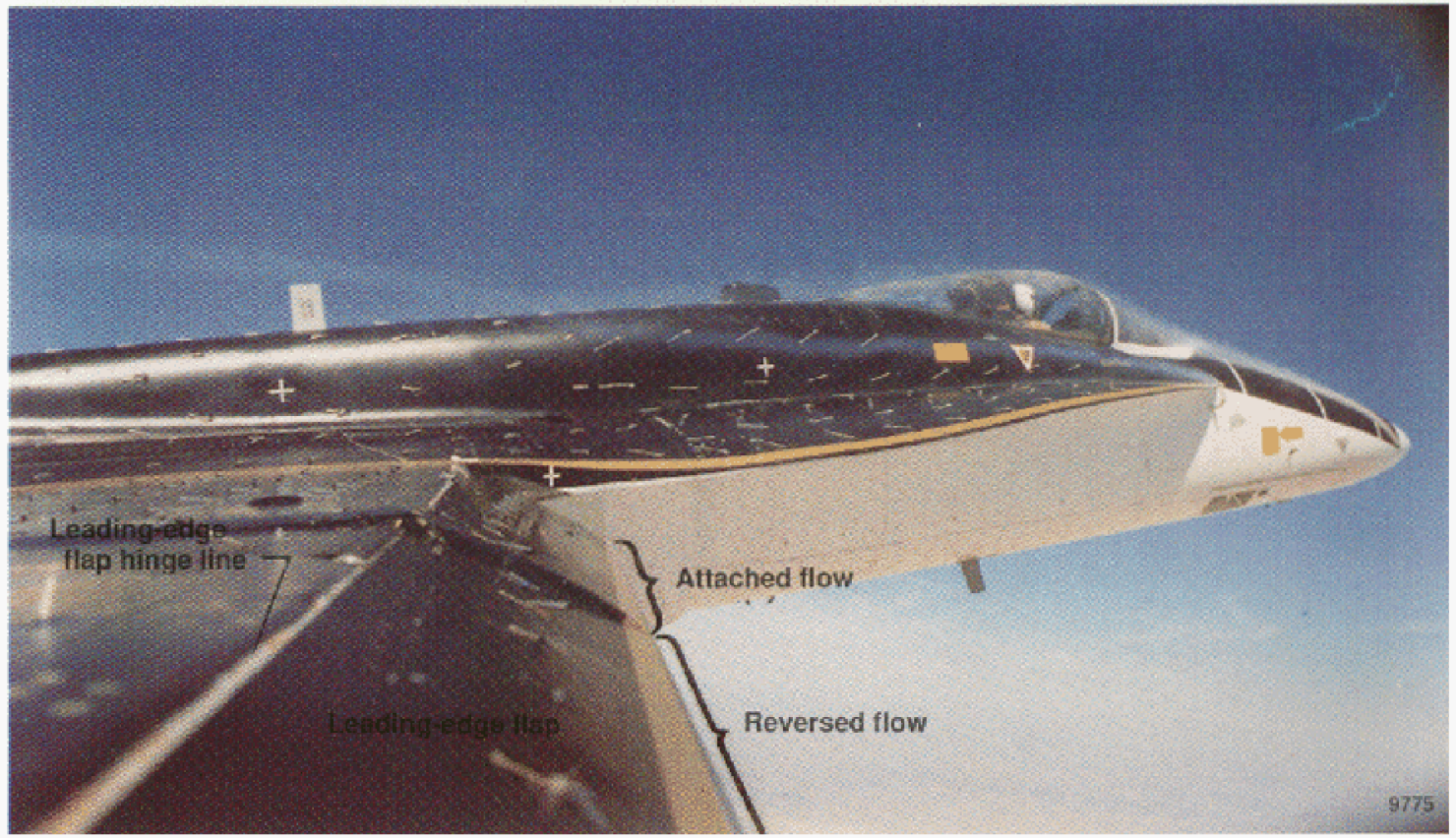

(b) Leading-edge flap, $\alpha=19.2^{\circ}$.

Figure 19. Surface flow visualization on right wing of F-18 HARV using flow tufts and cones, $\alpha \sim 20^{\circ}$. 


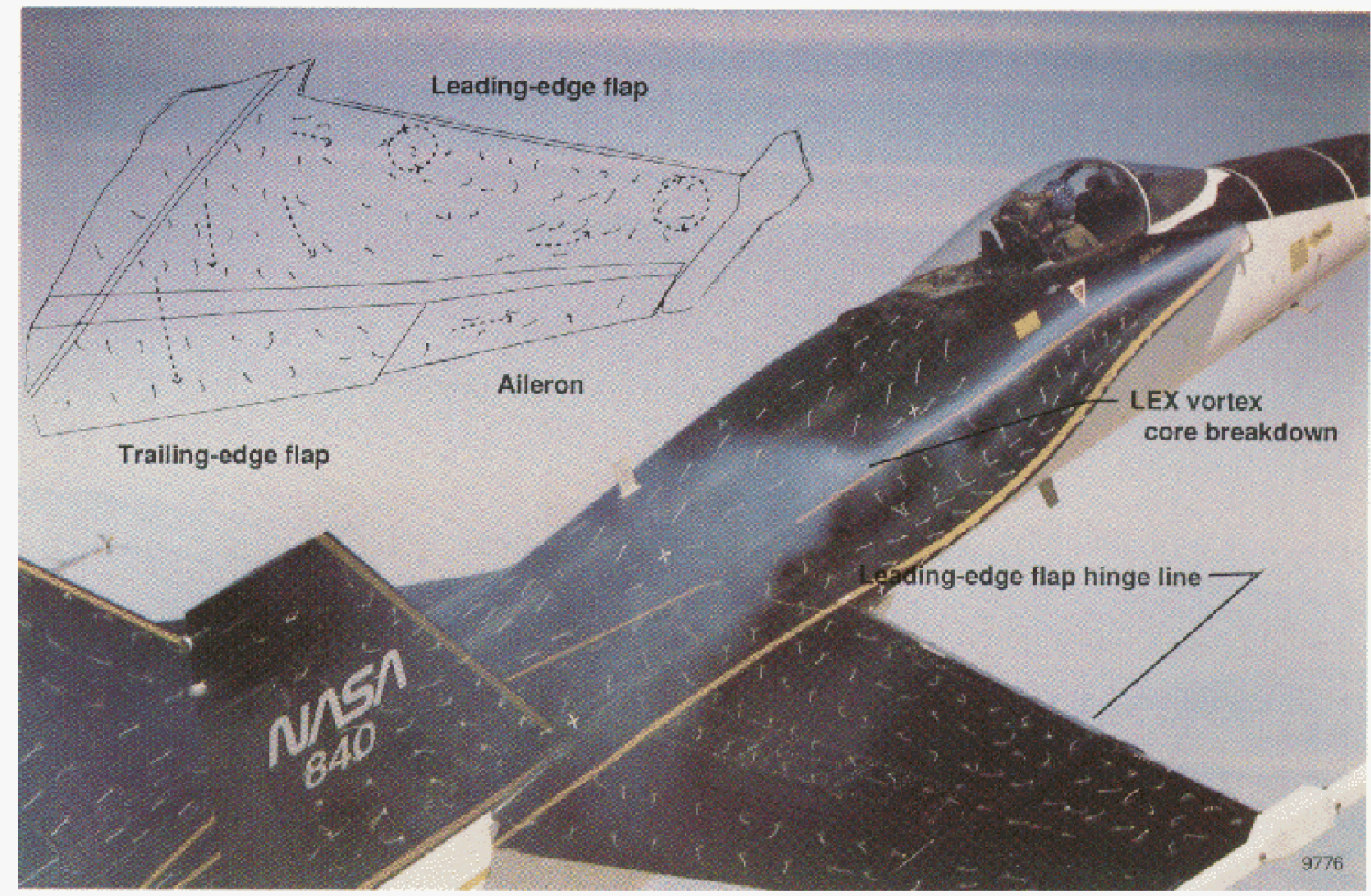

(a) View from chase aircraft, $\alpha \sim 25^{\circ}$.

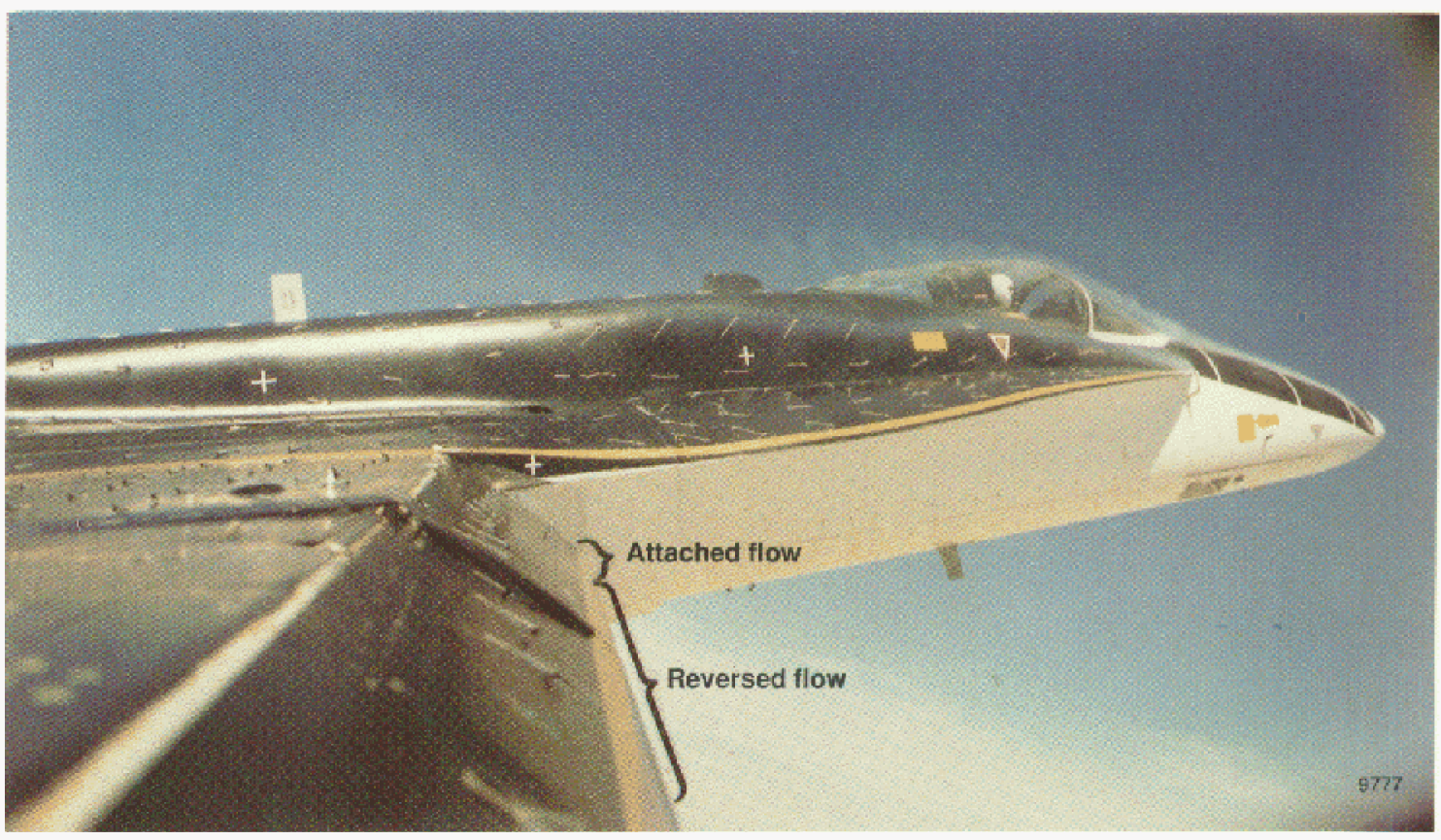

(b) Leading-edge flap, $\alpha=24.3^{\circ}$.

Figure 20. Surface flow visualization on right wing of F-18 HARV using flow tufts and cones, and comparison to oil flow visualization on 0.06 -scale model, $\alpha \sim 25^{\circ}$. 


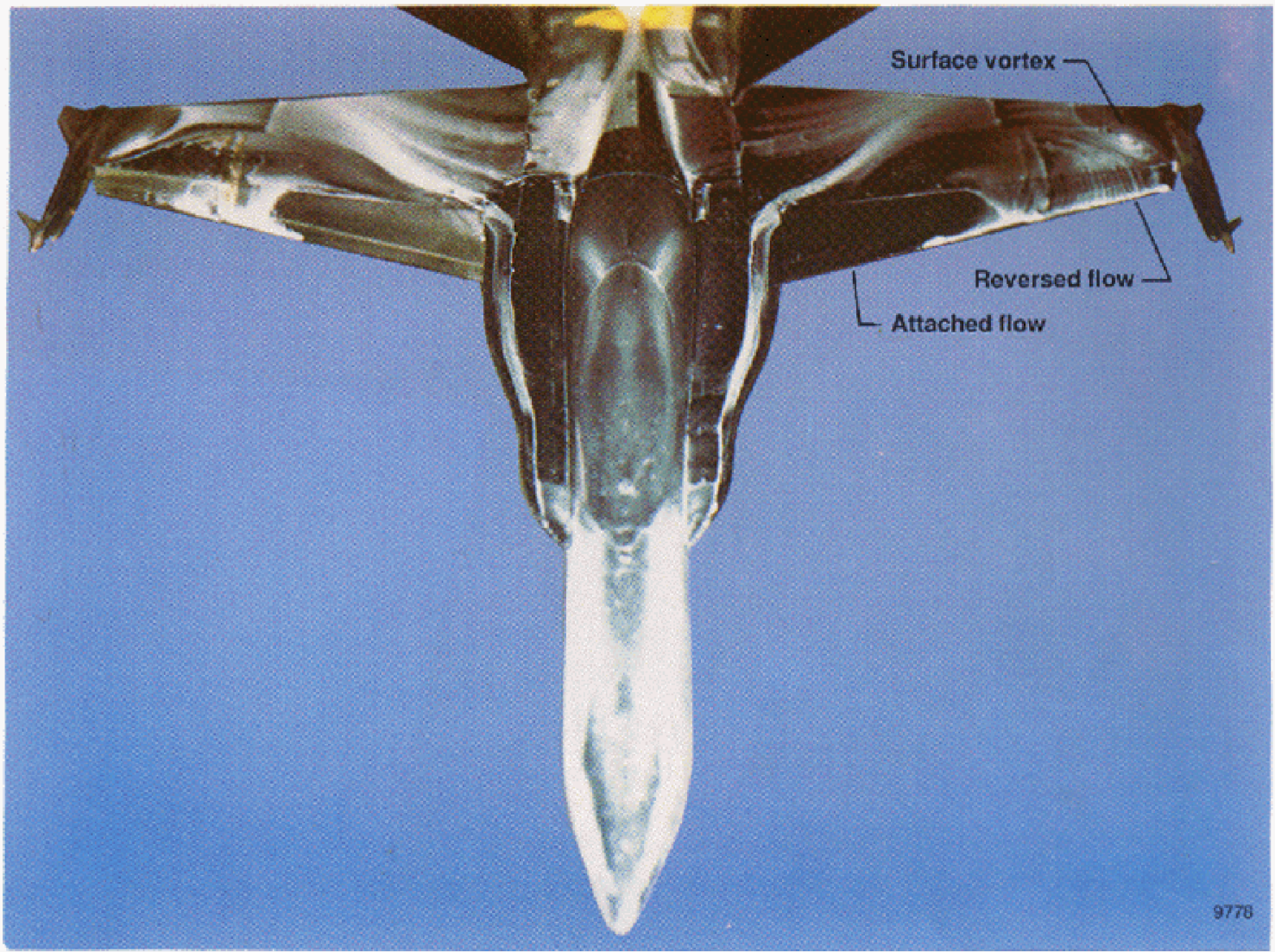

(c) Oil flow visualization of surface streamlines, 0.06-scale model of F-18 HARV, Langley Research Center 14- by 22-Foot Subsonic Tunnel, $\alpha=25^{\circ}$.

Figure 20. Concluded. 


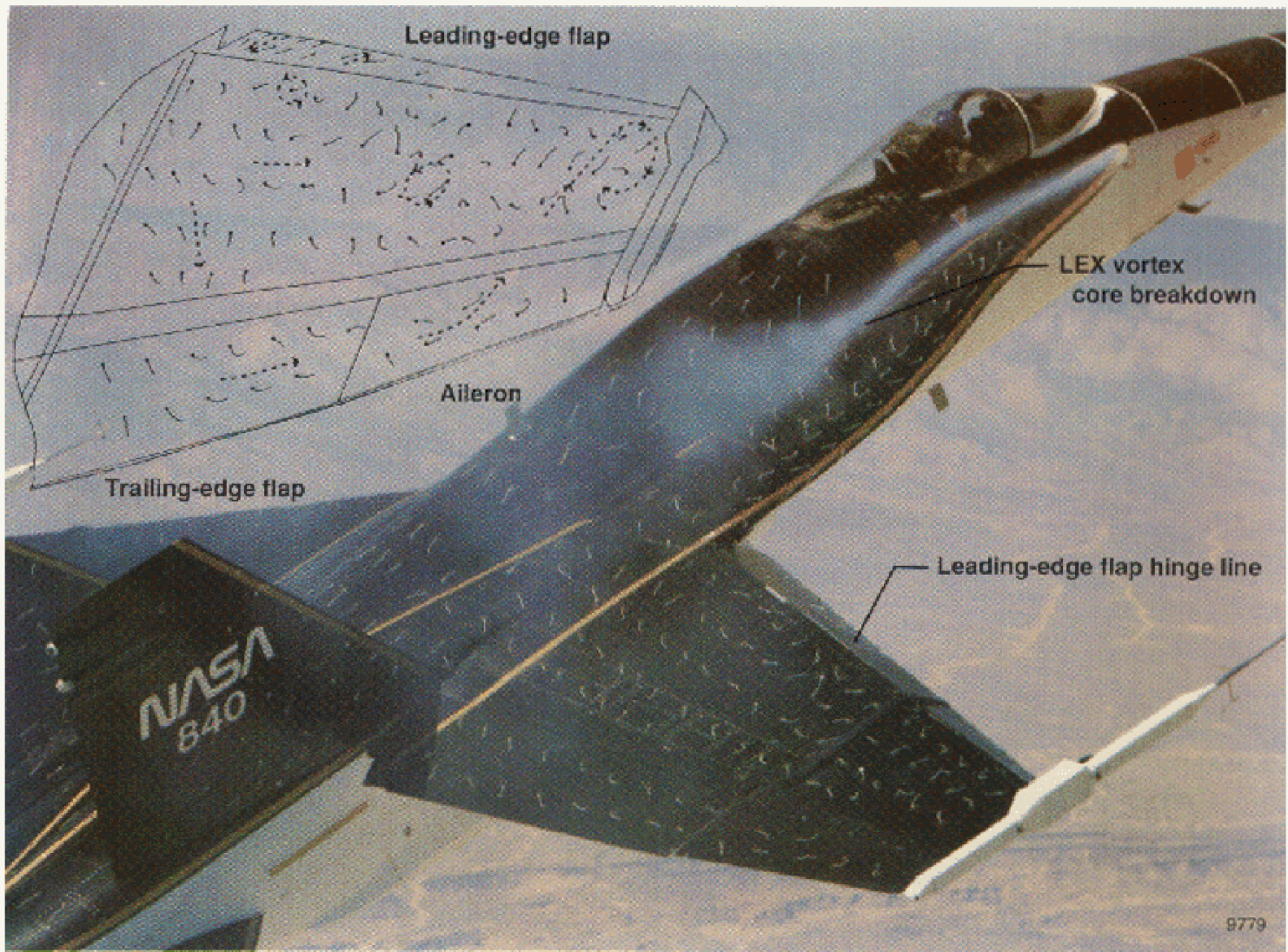

(a) View from chase aircraft, $\alpha \sim 30^{\circ}$.

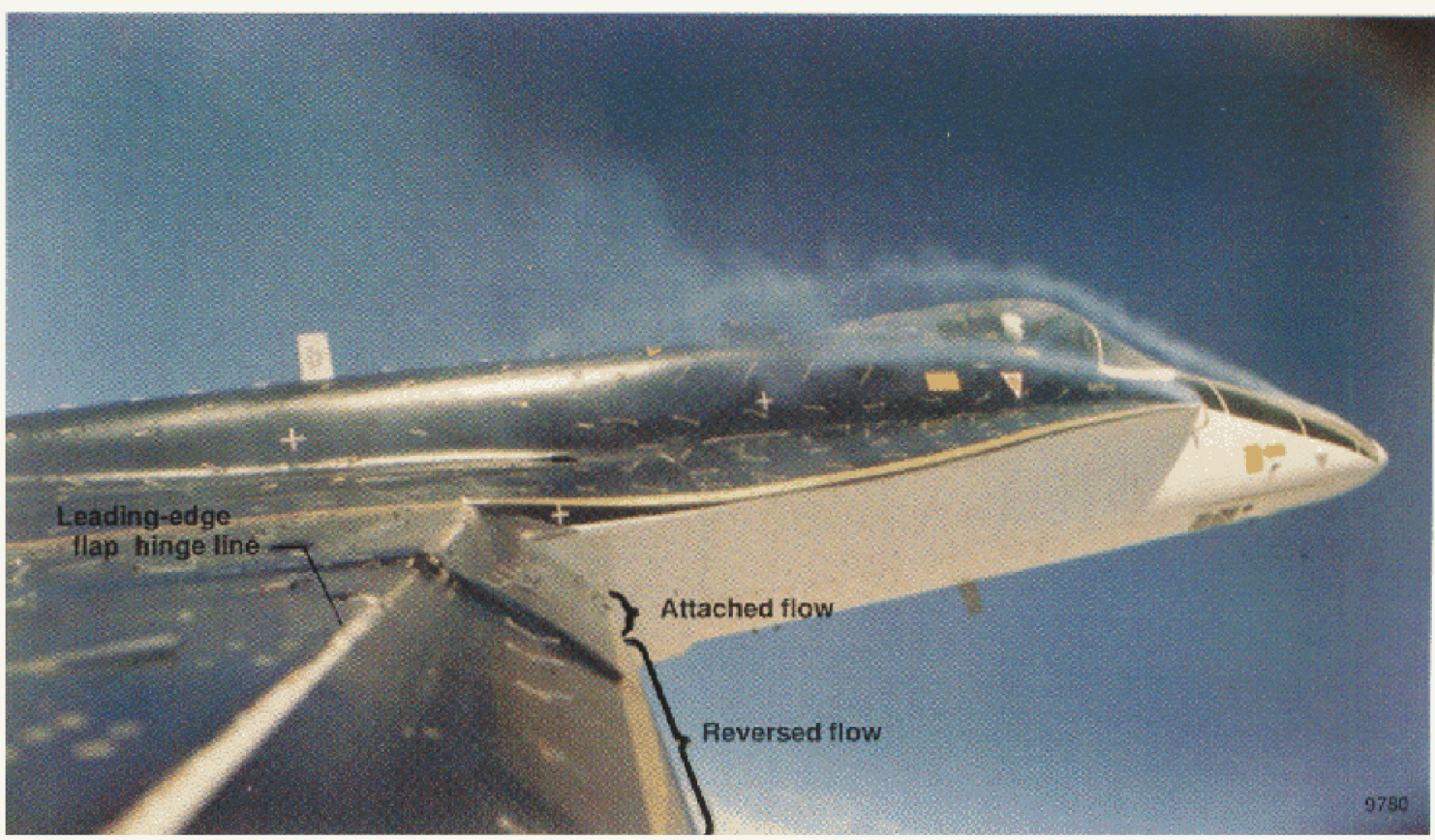

(b) Leading-edge flap, $\alpha=31.7^{\circ}$.

Figure 21. Surface flow visualization on right wing of F-18 HARV using flow tufts and cones, $\alpha \sim 30^{\circ}$. 


\begin{tabular}{|c|c|c|}
\hline \multicolumn{3}{|c|}{ Report Documentation Page } \\
\hline $\begin{array}{l}\text { 1. Report No. } \\
\text { NASA TM-4193 }\end{array}$ & 2. Government Accession No. & 3. Recipient's Catalog No. \\
\hline \multicolumn{2}{|c|}{$\begin{array}{l}\text { 4. Title and Subtitle } \\
\text { In-Flight Flow Visualization Characteristics of the NASA F-18 } \\
\text { High Alpha Research Vehicle at High Angles of Attack }\end{array}$} & $\begin{array}{l}\text { 5. Report Date } \\
\text { May } 1990 \\
\text { 6. Pertorming Organization Code }\end{array}$ \\
\hline \multirow{2}{*}{\multicolumn{2}{|c|}{$\begin{array}{l}\text { 7. Author(s) } \\
\text { David F. Fisher and John H. Del Frate (NASA Ames Research } \\
\text { Center); David M. Richwine (PRC Systems Services, Inc.) }\end{array}$}} & $\begin{array}{l}\text { 8. Performing Organization Report No. } \\
\text { H-1576 }\end{array}$ \\
\hline & & 10. Work Unit No. \\
\hline \multirow{2}{*}{\multicolumn{2}{|c|}{$\begin{array}{l}\text { 9. Performing Organization Name and Address } \\
\text { NASA Ames Research Center } \\
\text { Dryden Flight Research Facility } \\
\text { P.O. Box 273, Edwards, CA } 93523-0273\end{array}$}} & RTOP 505-68-71 \\
\hline & & 11. Contract or Grant No. \\
\hline \multirow{2}{*}{\multicolumn{2}{|c|}{$\begin{array}{l}\text { 12. Sponsoring Agency Name and Address } \\
\text { National Acronautics and Space Administration } \\
\text { Washington, DC } 20546\end{array}$}} & $\begin{array}{l}\text { 13. Type of Report and Period Covered } \\
\text { Technical Memorandum }\end{array}$ \\
\hline & & 14. Sponsoring Agency Code \\
\hline \multicolumn{3}{|l|}{ 15. Supplementary Notes } \\
\hline
\end{tabular}

16. Abstract

Surface and off-surface flow visualization techniques have been used to visualize the three-dimensional separated flows on the NASA F-18 high alpha research vehicle (HARV) at high angles of attack. Results near $\alpha=25^{\circ}$ to $26^{\circ}$ and $\alpha=45^{\circ}$ to $49^{\circ}$ are presented. Both the forebody and leading-edge extension (LEX) vortex cores and breakdown locations were visualized using smoke. Forebody and LEX vortex separation lines on the surface were defined using an emitted fluid technique. A laminar separation bubble was also detected on the nose cone using the emitted fluid technique and was similar to that observed in the windtunnel test, but not as extensive. Regions of attached, separated, and vortical flow were noted on the wing and the leading-edge flap using tufts and flow cones, and compared well with limited wind-tunnel results.

17. Key Words (Suggested by Author(s)/

F-18, flight test, flow visualization, separated flow, separation, transition, vortex, vortex core, wing rock

18. Distribution Statement

Unclassified - Unlimited

Subject category 02

19. Security Classif. (of this report) Unclassified

20. Security Classit. Iof this pagel
Unclassified

Unclassified

$\mid \begin{gathered}\text { 22. Price } \\ \mathrm{A03}\end{gathered}$

